\title{
Anti-leukemia properties of cadmium nanoparticles in in vitro and in vivo conditions: a chemobiological study
}

Yudi Miao' ${ }^{1}$, Behnam Mahdavi², Mohammad Mahdi Zangeneh ${ }^{3}$

${ }^{1}$ Department of Hematology, Shaanxi Provincial People's Hospital, Beilin District, Xi'an City, Shaanxi Province, China

2Department of Chemistry, Faculty of Science, Hakim Sabzevari University, Sabzevar, Iran

${ }^{3}$ Biotechnology and Medicinal Plants Research Center, Ilam University of Medical

Sciences, Ilam, Iran

Submitted: 8 August 2021; Accepted: 21 September 2021

Online publication: 15 October 2021

Arch Med Sci

DOI: https://doi.org/10.5114/aoms/142465

Copyright @ 2021 Termedia \& Banach

\section{Abstract}

Introduction: The present study investigated the anti-acute myeloid leukemia effects of Ziziphora clinopodioides Lam leaf aqueous extract conjugated cadmium nanoparticles.

Material and methods: To synthesize cadmium nanoparticles (CdNPs), Z. clinopodioides aqueous extract was mixed with $\mathrm{Cd}\left(\mathrm{NO}_{3}\right)_{2} \cdot 4 \mathrm{H}_{2} \mathrm{O}$. The characterization of the biosynthesized cadmium nanoparticles was carried out using many various techniques such as UV-Vis. and FT-IR spectroscopy, XRD, FE-SEM, and EDS.

Results: The uniform spherical morphology of NPs was proved by FE-SEM images with NPs the average size of $26.78 \mathrm{~nm}$. For investigating the antioxidant properties of $\mathrm{Cd}\left(\mathrm{NO}_{3}\right)_{2}$, Z. clinopodioides, CdNPs, and daunorubicin, the DPPH test was used. The cadmium nanoparticles inhibited half of the DPPH molecules in a concentration of $196 \mu \mathrm{g} / \mathrm{ml}$. To survey the cytotoxicity and anti-acute myeloid leukemia effects of $\mathrm{Cd}\left(\mathrm{NO}_{3}\right)_{2}, \mathrm{Z}$. clinopodioides, $\mathrm{Cd}$ NPs, and daunorubicin, MTT assay was used on the human acute myeloid leukemia cell lines i.e., murine C1498, 32D-FLT3-ITD, and Human HL-60/vcr. The $I C_{50}$ of the cadmium nanoparticles was 168,205 , and $210 \mu \mathrm{g} / \mathrm{ml}$ against murine C1498, 32D-FLT3-ITD, and human HL-60/vcr cell lines, respectively. In the in vivo part of the study, DMBA was used for inducing acute myeloid leukemia in mice. CdNPs, similar to daunorubicin, ameliorated significantly $(p \leq 0.01)$ the biochemical, inflammatory, RBC, WBC, platelet, stereological, histopathological, and cellular-molecular parameters compared to the other groups.

Conclusions: The cadmium nanoparticles had significant anti-acute myeloid leukemia effects. After approving the above results in the clinical trial studies, these cadmium nanoparticles can be used as a chemotherapeutic drug to treat acute myeloid leukemia in humans.

Key words: Ziziphora clinopodioides Lam, cadmium nanoparticles, daunorubicin, new chemotherapeutic drug, acute myeloid leukemia.

\section{Introduction}

Cancer is a genetic disease that includes 277 types of diseases. There are also more than 100,000 types of chemicals in our environment, of which only 35,000 have been analyzed and about 300 of them cause cancer. The remaining 65,000 chemicals in nature have not

\author{
Corresponding author: \\ Prof. Behnam Mahdavi \\ Department of Chemistry \\ Faculty of Science \\ Hakim Sabzevari \\ University \\ 96179-76487 Sabzevar \\ Iran \\ E-mail: b.mahdavi@hsu.ac.ir
}


yet been tested. Cancer occurs due to uncontrolled cell division, which is the result of environmental factors and genetic disorders [1-3]. The four key gene types involved in cancer cell conduction are DNA repair genes, tumor suppressor genes, oncogenes, and programmed death genes [2, 3]. If a genetic mutation is produced in a cell, normal cells deviate from their usual course and are affected by new commands that progress to cancer cells. In addition to chemicals, sunlight, shortwave, viruses and bacteria also have a special role in causing cancer $[4,5]$. Cancers have existed since the beginning of mankind. In recent decades, advances in computer molecular medicine have been able to not only study the causes and mechanisms of this deadly disease but also to perform better in its early diagnosis and treatment [5-7]. More than 50\% of cancers are currently being treated, especially if diagnosed early. Cancer can be treated in several ways: surgery, chemotherapy, radiation therapy, immunotherapy, gene therapy, or a combination of these. Due to the relative inefficiency and very severe side effects of chemotherapy drugs, researchers and scientists have sought a new formulation of various compounds, especially metallic nanoparticles [2-5].

In recent centuries, the application of nanotechnology has played an important role in the development of science. Nanoscience has shown that if we reduce the size to nanometers, unique properties such as optical properties, electrical conductivity, hardness, and chemical reaction will be obtained. Nanoparticles are widely used because of their high surface-to-volume ratio, small size, and excellent reactivity. One of the most important advances in nanotechnology is the production and application of nanoparticles in the biological sciences [5-7]. Nanoparticles are generally effective in a wide variety of sectors, where, if their production is based on green chemistry, they have great applications in the fields of food, medicine, cosmetics and health. Nanoparticles centered on inorganic materials such as magnetic metals, their oxides and alloys, and semiconductors have the most studies and potential in biomedicine from diagnosis to treatment of diseases [7-9]. The effects of nanoparticles should be predictable, controllable and achieve the desired results with minimal toxicity. Metallic nanoparticles used in treatment and diagnosis, in addition to being non-toxic, must be biocompatible and stable in vivo. Also, by making appropriate changes in the surface of metallic nanoparticles, they will have a wide range of applications by binding to biomolecules and various carriers to cross the cell membrane and target the desired part in the body. One of the important points in the production of nanoparticles is the use of cost-effective and effi- cient precursors [10-12]. There are three biological, chemical, and physical methods to synthesize nanoparticles. Chemical and physical methods are time-consuming and costly. In addition, these methods use some toxic additive chemicals that cause adverse effects on medical applications by adsorption on the surface. Applying the principles of green chemistry has decreased the use of toxic compounds or hazardous solvents, provided optimal regeneration conditions and ameliorated materials for the chemical processes, and raised new sources for green synthesis [8-10]. Therefore, one of the primary goals of green nanotechnology is to produce nanomaterials without harm to human health or the environment, and to develop and design nanomaterials and products that are suitable solutions to environmental problems. The synthesis of nanoparticles by similar biological methods results in greater catalytic activity and limits the use of toxic and expensive chemicals. In biological methods, plant extracts, enzymes or proteins carrying natural resources are used to produce or stabilize nanoparticles. The nature of the materials used to make nanoparticles influences the shape, structure and morphology of these nanoparticles [7-11]. Biological systems involved in the green synthesis of nanoparticles include plants and their derivatives, as well as microorganisms such as algae, fungi, and bacteria. Plant parts such as roots, leaves, stems, fruits, and tiny parts such as the kernel and skin of the fruit are suitable to synthesize nanoparticles because their extracts are rich in phytochemicals that act as stabilizing and reducing substances $[6,8]$. The use of natural plant extracts is a cheap and environmentally friendly process and does not require intermediate groups. Short time, no need for expensive equipment, precursors, high purity product and excellent quality without impurities are the features of this method. This is possible very quickly, at room temperature and pressure as well as easily on a large scale. Bio-reduction in the conversion of base metal ions is carried out by various plant metabolites such as alkaloids, phenolic compounds, terpenoids and coenzymes [9-12].

Recently, scientists have used the anti-leukemia effects of medicinal plants in several traditional medicines for synthesizing metallic nanoparticles containing natural compounds. Hemmati et al. showed that metallic nanoparticle-chitosan composite had excellent anti-acute myeloid leukemia against the human HL-60/vcr cell line [8]. Also, Zangeneh introduced a chemotherapeutic drug formulated by metallic nanoparticles containing natural compounds to treat acute myeloid leukemia [9]. In addition to the above studies, other studies investigated the anticancer properties of cadmium nanoparticles. In a study, Hossain and 
Mukherjee presented the excellent potential of cadmium nanoparticles in removing human cervical adenocarcinoma cells (HeLa) [10]. Also, in another study, Heidari indicated the significant role of cadmium nanoparticles in combination with UV radiation to remove tissue tumors [11]. Recently, scientists have used the anti-acute leukemia effects of medicinal plants for synthesizing metallic nanoparticles containing natural compounds. So far, the anti-acute leukemia effects of Euphoria hirta, Sophora subprostrata, Tinospora cordifolia, Barleria prionitis, Maytenus boaria, Lupinus perennis, Cephaelis acuminate, Solanum seaforthianum, Boswellia serrate, Phyllanthus niruri, Cephalotaxus harringtonia Drupacea, and Lavandula officinalis have been proved [12-15].

Z. clinopodioides aqueous extract is used in traditional medicine to treat inflammation, blood and gastrointestinal disorders, cutaneous wounds, and the common cold $[15,16]$. Many potential therapeutic properties of this plant, such as anti-inflammatory [17, 18], antifungal [17], antibacterial $[16,18,19]$, and antioxidant $[18,20]$, have been revealed. It has chemical antioxidant components including pulegone, $\alpha$ - and $\beta$-pinene, terpenoids, flavonoids, sis-isopulegone, thymol, piperitenone, and cineol [16, 18, 21, 22]. Probably, the remedial properties of this species are related to the above compounds.

Accordingly, the current study was conducted to compare the anti-acute myeloid leukemia effects of Z. clinopodioides Lam leaf conjugated cadmium nanoparticles with daunorubicin by investigating the biochemical, immunological, hematological, stereological, histopathological, and cellular-molecular approaches.

\section{Material and methods}

\section{Material}

Phosphate buffer solution (PBS), Sabouraud Dextrose Agar, Sabouraud Dextrose Medium, Muller Hinton Agar, Mueller Hinton Medium, carbazole reagent, 4-(dimethylamino)benzaldehyde, Ehrlich solution, dimethyl sulfoxide (DMSO), Dulbecco's Modified Eagle Medium (DMED), hydrolysate, decamplmaneh fetal bovine serum, borax-sulfuric acid mixture, 2,2-diphenyl-1-picrylhydrazyl (DPPH), and antimycotic antibiotic solution were all obtained from Sigma-Aldrich (USA).

\section{Synthesis of CdNPs}

To obtain the aqueous extract of the plant (Figure 1), $100 \mathrm{~g}$ of dried branches of $Z$. clinopodioides leaves were poured in a container containing $1000 \mathrm{ml}$ of boiled water, and the container lid was tightly closed for $4 \mathrm{~h}$. Then, the container's content was filtered, and the remaining liquid was placed on a bain-marie to evaporate. Finally, a tarlike material was obtained, which was powdered by a freeze dryer [23].

$20 \mathrm{ml}$ of the extract $(100 \mu \mathrm{g} / \mathrm{ml})$ was added to $20 \mathrm{ml}$ of $\mathrm{Cd}\left(\mathrm{NO}_{3}\right)_{2} \cdot 4 \mathrm{H}_{2} \mathrm{O}(0.15 \mathrm{mM})$. The reaction mixture was stirred for $12 \mathrm{~h}$ at room temperature. The appearance of a yellow colloidal solution indicated the formation of cadmium nanoparticles. The obtained CdNPs were washed three times with water and centrifuged at $10000 \mathrm{rpm}$ for 15 min. The common techniques of organic chemistry, i.e. FT-IR and UV-Vis. spectroscopy, SEM, XRD, and EDS were used to characterize of CdNPs [23].

\section{DPPH test}

Free radicals are unstable atoms that have one or more unpaired electrons. These active species are very harmful due to their high reactivity. They are most often formed when oxygen molecules in the body split into separate unstable atoms. This process can turn into a chain reaction. Free radicals' excessive production in the body causes cell damage and oxidative stress. Genetics and the environment affect the extent of free radical damage in individuals. These active molecules are produced as part of the body's natural biological processes. One of the most important free radicals is DPPH. DPPH is widely used to study the antioxidant activities of natural compounds and nanoparticles [24].

In this method, the antioxidant activity of nanoparticles is measured for DPPH radical scavenging. The basis of the action is the reduction of the alcoholic solution of DPPH in the presence of hydrogen-giving antioxidants, especially phenolic compounds. To achieve the $I_{50}$ of the samples, 11 different concentrations of nanoparticles were prepared and the percentage inhibition versus

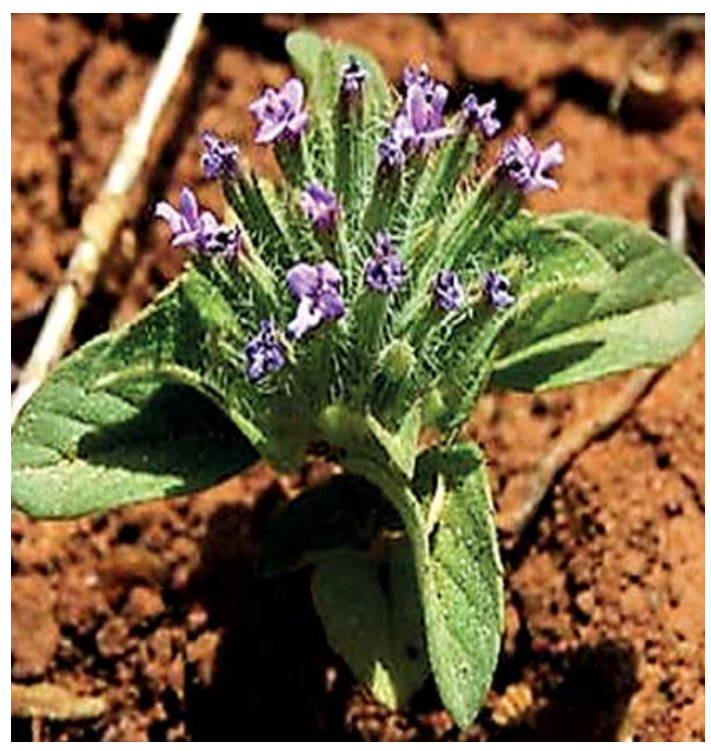

Figure 1. Image of Ziziphora clinopodioides Lam 
concentration was plotted. In practice, $300 \mu \mathrm{l}$ of $1 \mathrm{M} \mathrm{DPPH}$ was combined with $100 \mu \mathrm{l}$ of diluted sample to a final volume of $2 \mathrm{ml}$ using methanol. After $0.5 \mathrm{~h}$ in the dark, the absorbance was read at $517 \mathrm{~nm}$ and the inhibitory percentage was obtained using the following formula:

$$
\text { Inhibition }(\%)=\frac{\text { Sample A }}{\text { Control A }} \times 100 \text {. }
$$

In this formula, "Control A" shows the negative control of light absorption that lacks nanoparticles, and "Sample A" expresses the amount of light absorption of different concentrations of nanoparticles [24].

\section{Analysis of cytotoxicity of CdNPs}

In this experiment, $\mathrm{Cd}\left(\mathrm{NO}_{3}\right)_{2}$, Z. clinopodioides, CdNPs, and daunorubicin were examined for their cytotoxicity activities against HUVEC, murine C1498, 32D-FLT3-ITD, and human HL-60/vcr cell lines using the common cytotoxicity test, i.e., MTT assay in vitro.

Because nanoparticles are not soluble directly in 1640-RPMI medium and also the solvent of dimethyl sulfoxide nanoparticles (DMSO) itself has cytotoxic effects, to eliminate the effect of this substance on treated cells, its amount in the final solution is considered less than 1\%. Dimethyl sulfoxide is not toxic to concentrations less than $1 \%$ and the concentration of this solvent is important in this regard. For this purpose, $1000 \mu \mathrm{g}$ of nanoparticle was dissolved in $100 \mu$ l of dimethyl sulfoxide solvent after weighing. Then $1 \mathrm{ml}$ of culture medium was added for better dissolution and finally the volume of solution was increased to $24 \mathrm{ml}$ using culture medium. Then, successive dilutions of this stock were used in the proportions of $1-1000 \mu \mathrm{g} / \mathrm{ml}$. Eleven concentrations were used for the cell lines [25].

In this study, 100 microliters of culture medium containing $10^{4}$ cells per plate 96 were placed. After $24 \mathrm{~h}$, concentrations of $1-1000 \mathrm{\mu g} / \mathrm{ml}$ of nanoparticles were added to the cells and incubated for 24,48 , and $72 \mathrm{~h}$, respectively. After these times, $20 \mu \mathrm{l}$ of MTT plate with a concentration of $5 \mathrm{mg} / \mathrm{ml}$ was added to each cell and incubated in the dark for another $4 \mathrm{~h}$. After some time, the MTT medium was carefully removed, and $200 \mu$ l of acidified isopropanol were added to each plate to remove the purple formanes. After $15 \mathrm{~min}$ of incubation at room temperature, the light absorption of each well was read using an ELISA at $570 \mathrm{~nm}$ against a reference wavelength of $690 \mathrm{~nm}$. The findings were reported as cell survival and $I C_{50}$ (concentration that inhibits cell growth up to $50 \%$ ) based on the concentration curve $(\mu \mathrm{g} / \mathrm{ml})$ [25].

It should be noted that the effect of each concentration of the nanoparticles on cell lines was investigated in five independent experiments. Ac- cording to the values of light absorption obtained by the ELISA reader, the percentage of growth inhibition related to each concentration was calculated using the following formula: Cell viability (\%) $=($ Sample A/Control A $) \times 100$.

Finally, linear regression was done to determine $I C_{50}$, which indicates the nanoparticle concentration which causes $50 \%$ cancer cell growth inhibition. Using the curve, the line equation for cancer cells was obtained, then by replacing 50\% inhibition in the equation, the $I C_{50}$ value for cancer cells was obtained [25].

\section{In vivo design}

At the beginning of the study, acute myeloid leukemia induction was done with $40 \mathrm{mg} / \mathrm{kg}$ body weight intravenous injection of 7,12-dimethylbenz[a]anthracene (DMBA) biweekly for 6 weeks in 75 animals. One group was considered as a healthy control group and injected with normal saline $(n=15)$. After 6 weeks, the 75 DMBAtreated mice were randomly divided into five subgroups, including untreated receiving distilled water, and four groups receiving $1 \mathrm{mg} / \mathrm{kg}$ body weight intravenous injection of $\mathrm{Cd}\left(\mathrm{NO}_{3}\right)_{2}$, Z. clinopodioides, CdNPs, and daunorubicin separately. During this period, the healthy control group received normal saline. The mice underwent injection treatment for 24 days. Dosing was repeated for a total of 6 cycles of dosing. The mice were weighed seven times during the study. At the end of day 24 of treatment after anesthetizing the animals, the blood samples were drawn immediately from the animals' hearts. Also, the mice livers and spleens were harvested to analyze biochemical and stereological factors [26].

In serological parameters, the volumes of hepatocyte, central vein, portal vein, sinusoid, bile duct, and hepatic artery in the liver and the volumes of white pulp, red pulp, vessels, marginal zone, and follicle in the spleen were investigated [13].

Biochemical (SOD, CAT, GR, GPX, ALP, AST, ALT, GGT, cholesterol, LDL, HDL, triglyceride, total protein, albumin, total and conjugated bilirubin, glucose, urea, creatinine, ferrous, ferritin, and erythropoietin), immunological (pro-inflammatory (IL-1, IL-6, IL-12, IL-18, IFN- $\gamma$, and TNF- $\alpha$ ) and anti-inflammatory (IL-4, IL-5, IL-10, IL-13, and IFN- $\alpha$ ) cytokines) parameter concentrations were measured in the serum by the ELISA procedure and determined using kits (Ziest Chem Diagnostics) according to the manufacturer's instructions [27, 28]. The number of total WBCs, blasts, lymphocytes, monocytes, neutrophils, eosinophils, basophils, platelets, RBCs, and $\mathrm{nRBC}$, and the levels of $\mathrm{HB}, \mathrm{PCV}, \mathrm{MCV}, \mathrm{MCH}$, and $\mathrm{MCHC}$ were analyzed in the plasma by an automatic hematology analyzer (Sysmex XS 800i) [26]. 
In the cellular and molecular part of this study, the mRNA expression of S1PR1 or sphingosine1-phosphate receptor-1 and S1PR5 or sphingosine-1-phosphate receptor-5 was measured by real-time PCR in blood lymphocytes [26].

All stereological, biochemical, immunological, hematological, and cellular and molecular analyses were done in duplicate.

\section{Statistical analysis}

SPSS statistical software version 22 was used for data analysis and the findings were determined as the mean standard deviation of 5 replications. Data were analyzed using one-way analysis of variance and Duncan's post hoc test and the significance level in the test was considered 0.05.

\section{Results and discussion}

Recently, the anti-angiogenic and anti-cancer properties of metallic nanoparticles have been determined and the findings have revealed that metallic nanoparticles can be used as a unique anti-cancer supplement. But the organic solvents used to produce these nanoparticles are toxic and can have devastating environmental effects. Hence there is a great tendency to use healthy methods for synthesizing metallic nanoparticles. Recently, studies have begun under the title "green chemistry", which seeks an environmentally friendly way for nanoparticle synthesis [1-3]. In recent years, metallic nanoparticles have been synthesized extracellularly using various plant and microbial extracts. In addition, many studies are underway to investigate the antibacterial, antioxidant and anti-tumor properties of these natural products [12-14]. In this regard, a study assessed the antibacterial activities of metallic nanoparticles synthesized biologically. Another study evaluated the anticancer, antibacterial, and antioxidant properties of metallic nanoparticles yielded by plant extract [5-10]. The anti-inflammatory, antioxidant and antimicrobial effects of metallic nanoparticles green-synthesized by medicinal plants are well known [12-14]. It also affects a range of molecular targets and signaling pathways, such as NF-JB, AKT/mTOR, and HIF-1A, and as a result, it plays a role in inhibiting cancer cell proliferation, metastasis, angiogenesis and also inducing apoptosis. Previous studies have also shown that metallic nanoparticles containing medicinal plants cause deformity and perforation of cancer cells, resulting in their death [10-14].

\section{In vitro anti-acute myeloid leukemia property of CdNPs}

Investigation of cell proliferation and survival is one of the most important and basic techniques in cell laboratories. This study requires accurate quantification of the number of living cells in the cell culture medium. Therefore, cell survival calculation methods are necessary to optimize cell culture conditions, evaluate cell growth factors, detect antibiotics and anticancer drugs, evaluate the toxic effects of environmental pollutants, and study apoptosis. Many methods can be used for such purposes, but indirect methods using fluorescent or dye (chromogenic) markers provide very fast large-scale methods. Among these methods, measurement of cell survival by the MTT method (3-(4,5-dimethylthiazol-2-yl)-2,5-diphenyltetrazolium bromide) is the most widely used method. It is a colorimetric method to study cell proliferation and survival, introduced in 1983 by Mossman. The method basis is based on mitochondrial activity. Mitochondrial activity in living cells is stable and therefore a rise or reduction in the living cell number is linearly related to mitochondrial activity [2527]. MTT tetrazolium dye is revived in active cells. Mitochondrial dehydrogenases in living cells break the tetrazolium ring and yield NADPH and NADH, leading to formation of a purple insoluble deposit called formazan. This precipitate can be dissolved by dimethyl sulfoxide or isopropanol. On the other hand, dead cells do not have this ability and therefore do not reveal a signal. Dye formation is used as a marker of living cells. The color intensity produced is measured at a wavelength of 540 to $630 \mathrm{~nm}$ and is directly proportional to the living cell number. High safety and providing a colorimetric and non-radioactive system are important advantages of this method. This kit is very easy to use, has high sensitivity and accuracy and can detect less than 950 cells. On the other hand, it has high efficiency for measuring cell proliferation, survival and mortality, and its implementation method does not require time-consuming washing steps and transfer from one plate to another. Examples studied in this method are adhesive or suspended cells and proliferating or non-proliferating cells [25-29].

In the current experiment, the cells treated with many concentrations of $\mathrm{Cd}\left(\mathrm{NO}_{3}\right)_{2}$, Z. clinopodioides, CdNPs, and daunorubicin were examined by the MTT test for $48 \mathrm{~h}$ regarding the cytotoxic effects on normal (HUVEC) and acute myeloid leukemia (32D-FLT3-ITD, murine C1498, and human HL-60/vcr) cell lines (Figure 2). The absorbance rate was determined at $570 \mathrm{~nm}$, which indicated extraordinary viability on the normal cell line (HUVEC) even up to $1000 \mu \mathrm{g} / \mathrm{ml}$ for $\mathrm{Cd}\left(\mathrm{NO}_{3}\right)_{2}$, Z. clinopodioides, CdNPs, and daunorubicin.

In the case of acute myeloid leukemia cell lines, their viability decreased dose-dependently in the presence of $\mathrm{Cd}\left(\mathrm{NO}_{3}\right)_{2}, Z$. clinopodioides, CdNPs, and daunorubicin. The $\mathrm{IC}_{50}$ values of $\mathrm{Cd}\left(\mathrm{NO}_{3}\right)_{2}$, Z. clinopodioides, CdNPs, and daunorubicin 
A

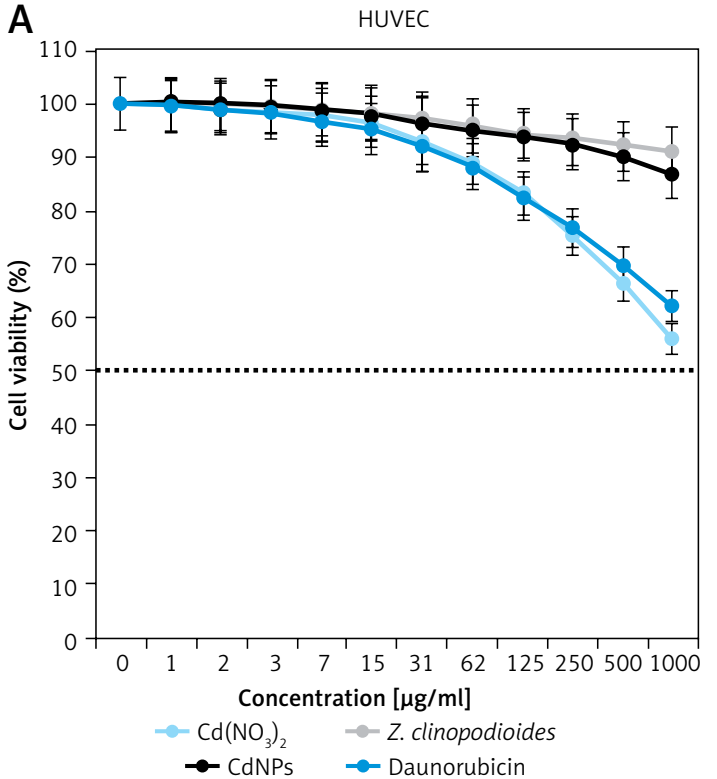

C

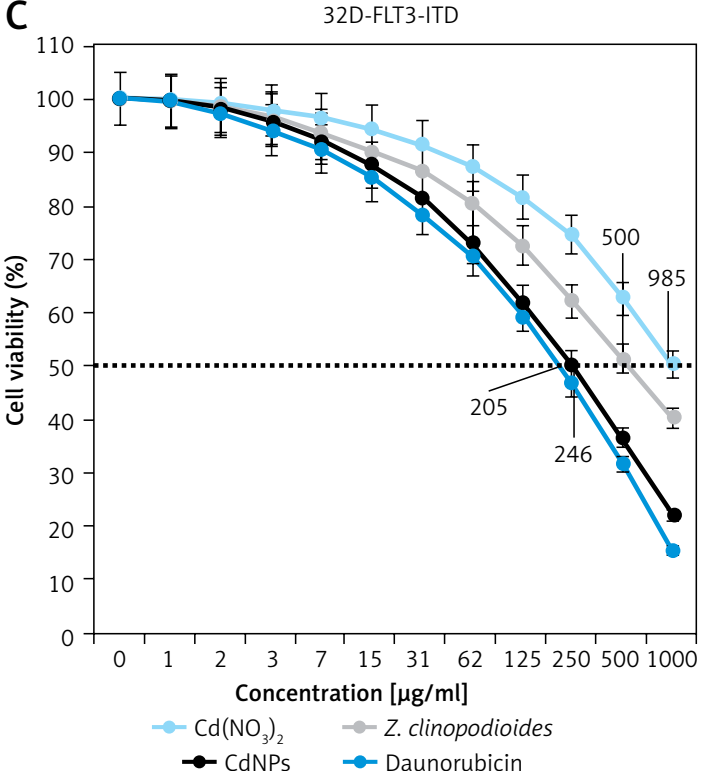

B

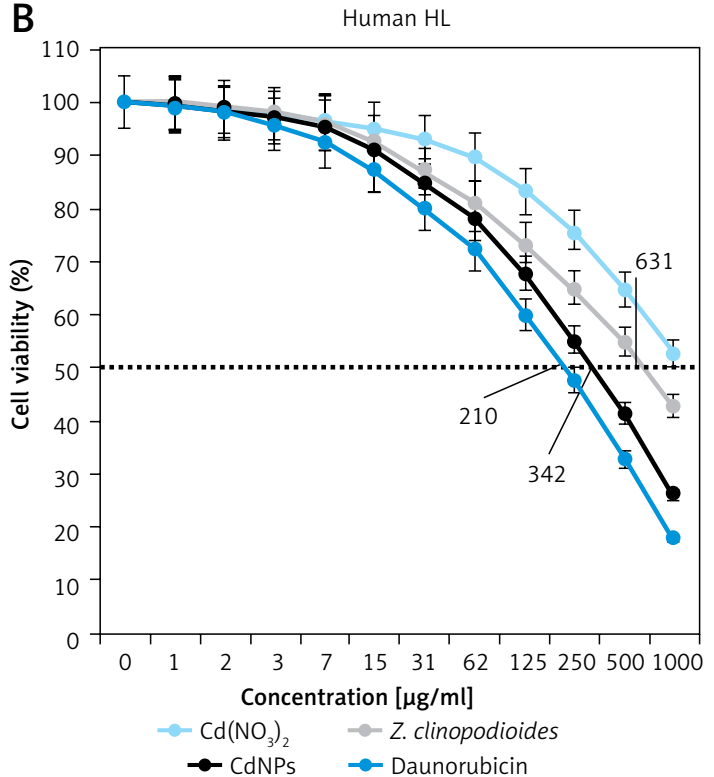

D

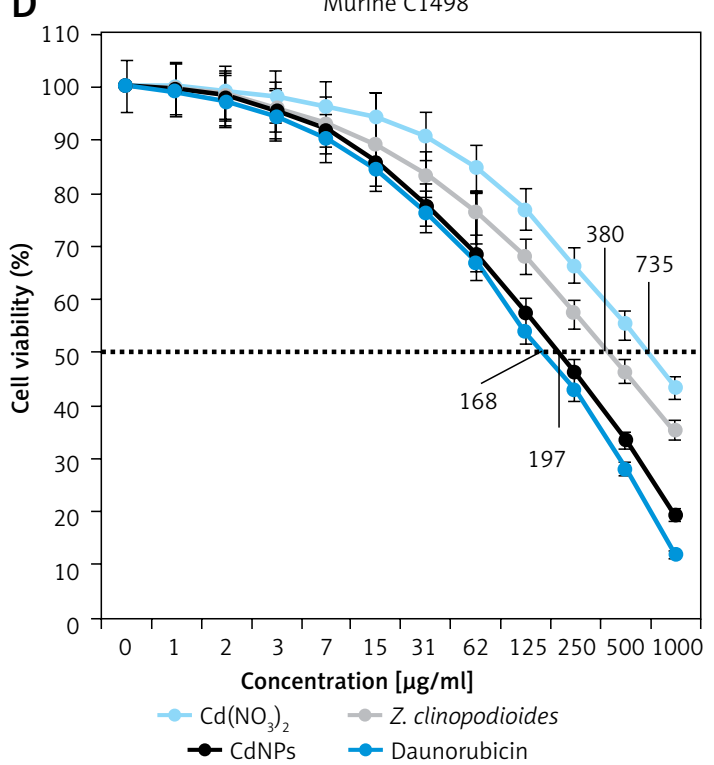

Figure 2. Percent viability measured on HUVEC (A), human HL-60/vcr (B), 32D-FLT3-ITD (C), and murine C1498 (D) after treatment with $\mathrm{Cd}\left(\mathrm{NO}_{3}\right)_{2}$, Z. clinopodioides leaf aqueous extract, CdNPs, and daunorubicin

against the murine C1498 cell line were 735,380 , 197 , and $168 \mu \mathrm{g} / \mathrm{mL}$, respectively, and against the 32D-FLT3-ITD cell line were 985, 500, 246, and $205 \mu \mathrm{g} / \mathrm{ml}$, respectively. Regarding the human $\mathrm{HL}-60 / \mathrm{vcr}$, the $\mathrm{IC}_{50}$ values of $Z$. clinopodioides, CdNPs, and daunorubicin were 641, 342, and 210, respectively. The size of the nanoparticles affects their anticancer properties, so that the nanoparticles with the size lower than $100 \mathrm{~nm}$ have unique anticancer potential [29].

\section{Antioxidant property of CdNPs against DPPH}

Oxidation is the transfer of electrons from an atom and is the aerobic life and metabolism part of living organisms. Oxygen is the receptor for electrons in the electron transport system, which yields energy from ATP (adenosine triphosphate) in the body. Under certain conditions, undergo single electron transfer and release free radicals. When oxygen gains a single electron, it is called a reactive oxygen species (ROS). Oxidative loss to proteins, DNA, and other macromolecules is one of the internal causes of degenerative diseases such as aging, cardiovascular disease, cancer, immune system deficiency, cataracts, and abnormal brain function. Single oxygen, high-energy, mutagenic oxygen, can be produced by lipid peroxidation by the transmission of energy from light or the respiratory tract of neutrophils $[30,31]$ Some free radicals have positive roles such as 
regulating cell growth, phagocytosis, energy production, intracellular signals, or the synthesis of important biological compounds. Antioxidants produced in the body fight free radicals with two systems: enzymatic defense and non-enzymatic defense. Superoxide dismutase, catalase, and glutathione peroxidase metabolize lipid peroxide, hydrogen peroxide, and superoxide and prevent the production of toxic hydroxyl radicals [32, 33]. In non-enzymatic defense, there are two classes of antioxidants, fat-soluble (such as carotenoids and vitamin E) and water-soluble (glutathione and vitamin C), that trap free radicals. These two systems help neutralize oxidants. However, oxidants can escape from antioxidants and damage tissues. In this case, the activated antioxidant repair system (which comprises the enzymes lipase, protease, transferase and DNA repair enzymes) counteracts the oxidant effects. However, due to deficiencies in the production of antioxidants in the body or due to physiopathological factors and situations (such as smoking, air pollution, UV radiation, diets containing high unsaturated fatty acids, inflammation, ischemia, bleeding, etc.) in which ROS are yielded in large quantities at the wrong place and time, oral antioxidants are need-

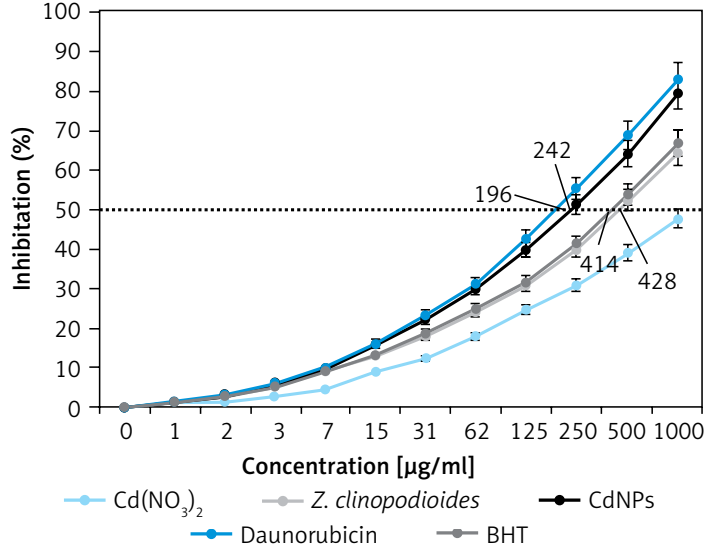

Figure 3. Antioxidant activity of $\mathrm{Cd}\left(\mathrm{NO}_{3}\right)_{2}$, Z. clinopodioides leaf aqueous extract, CdNPs, daunorubicin, and BHT

ed to counteract the oxidative damage cumulative effects [30-33].

In our research, $Z$. clinopodioides leaf aqueous extract, daunorubicin, and CdNPs, similar to BHT, showed a notable concentration-dependent $\mathrm{DPPH}$ radical scavenging effect. The $\mathrm{IC}_{50}$ values of Z. clinopodioides leaf aqueous extract, BHT, daunorubicin, and CdNPs were 428, 414, 242, and 196, respectively (Figure 3).

A

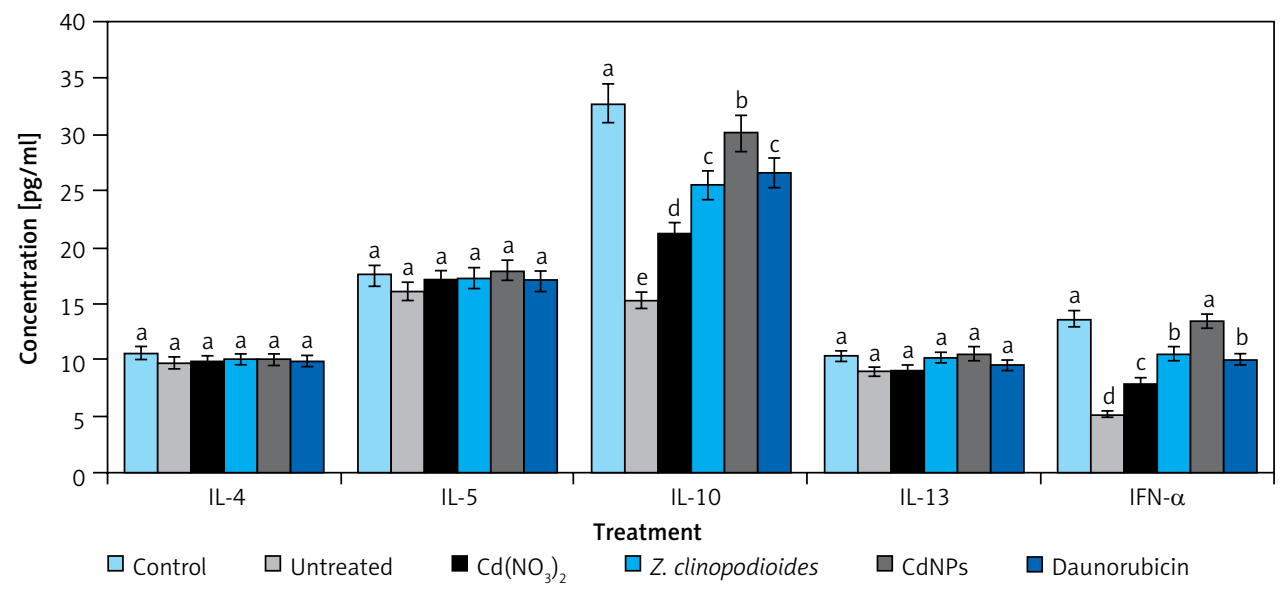

B

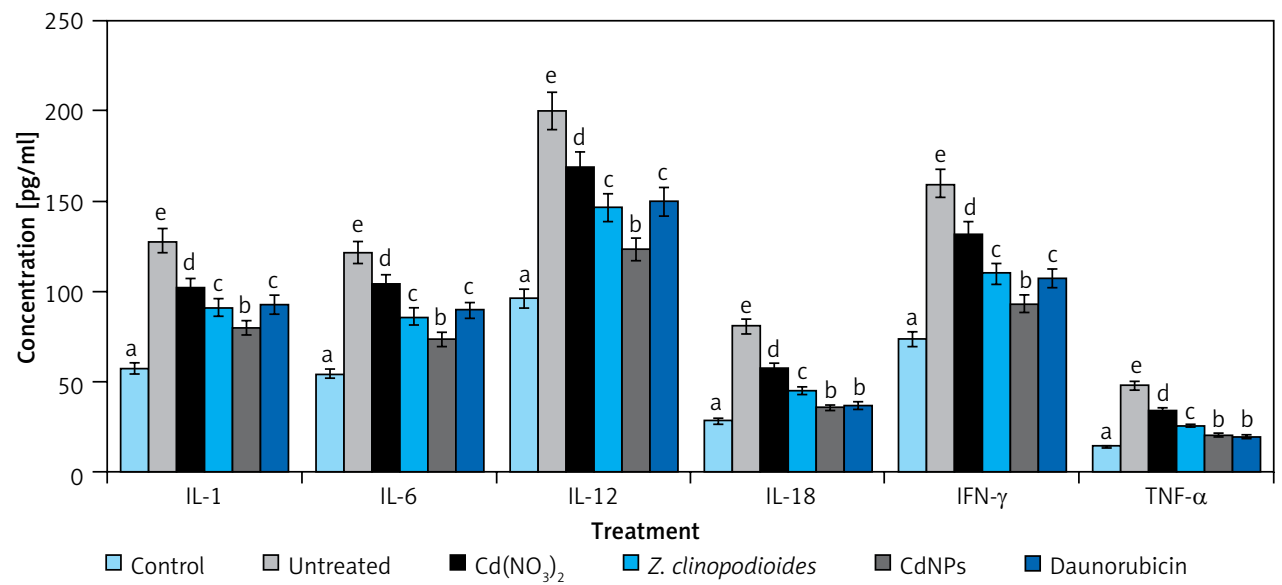

Figure 4. Levels of immunological parameters in tested groups $(p \leq 0.01)$. A - Anti-inflammatory cytokines. B - Pro-inflammatory cytokines 
The interaction between the $Z$. clinopodioides leaf aqueous extract, daunorubicin, and CdNPs and DPPH might have occurred through the transfer of electrons and hydrogen ions to 2,2-diphenyl-1-picrylhydrazyl radical to form a stable 2,2-diphenyl-1-picrylhydrazine molecule (DPPH) [30-34].

\section{In vivo anti-acute myeloid leukemia properties of CdNPs}

To induce acute myeloid leukemia, DMBA was used. DMBA causes many problems in the body such as self-immune, hepatic, splenic, vascular, central nervous system, respiratory, and renal disorders and acute myeloid leukemia [35]. In detail, DMBA-induced acute myeloid leukemia reduces the platelet, lymphocyte, and RBC counts and increases the WBC, blast, eosinophil, neutrophil, monocyte, and basophil counts [26, 36-38].

As shown in Figure 4, the anti-inflammatory cytokines IFN- $\alpha$, IL-4, IL-5, IL-10, and IL-13 decreased significantly $(p \leq 0.01)$ and the pro-inflammatory cytokines IFN- $\gamma$, TNF- $\alpha$, IL-1, IL-6, IL-12, and IL-18 increased significantly $(p \leq 0.01)$ in the DMBA-treated group.

$\mathrm{Cd}\left(\mathrm{NO}_{3}\right)_{2}$, Z. clinopodioides leaf aqueous extract, CdNPs, and daunorubicin significantly $(p \leq 0.01)$

ameliorated the pro-inflammatory and anti-inflammatory cytokines as compared to the untreated group. The best results were observed in the CdNP-treated group.

In the present study, the total WBC, blasts, monocyte, neutrophil, eosinophil, basophil, and nRBC counts increased significantly $(p \leq 0.01)$ and the RBC, platelet, and lymphocyte counts and the other RBC parameters including $\mathrm{Hb}, \mathrm{PCV}$, $\mathrm{MCV}, \mathrm{MCH}$, and $\mathrm{MCHC}$ decreased significantly $(p \leq 0.01)$ in the DMBA-treated group (Figures 5,6$)$. The above results show that DMBA successfully induced acute myeloid leukemia in mice.

$\mathrm{Cd}\left(\mathrm{NO}_{3}\right)_{2}$, Z. clinopodioides leaf aqueous extract, CdNPs, and daunorubicin ameliorated significantly $(p \leq 0.01)$ the hematological parameters. The best results were obtained in the CdNP and daunorubicin-treated group. In the present study, the anti-hemolytic activity of $\mathrm{Cd}\left(\mathrm{NO}_{3}\right)_{2}$, Z. clinopodioides leaf aqueous extract, CdNPs, and daunorubicin may be associated with their antioxidant potential. Many studies, similarly to our study, have revealed significant antioxidant effects of cadmium nanoparticles [10, 11, 39-41].

In our study, mRNA expression of S1PR1 in lymphocytes increased by 33.2, 8.1, 14.7, 20, and 23.1 fold in control, $\mathrm{Cd}\left(\mathrm{NO}_{3}\right)_{2}$, Z. clinopodioides leaf

B

A
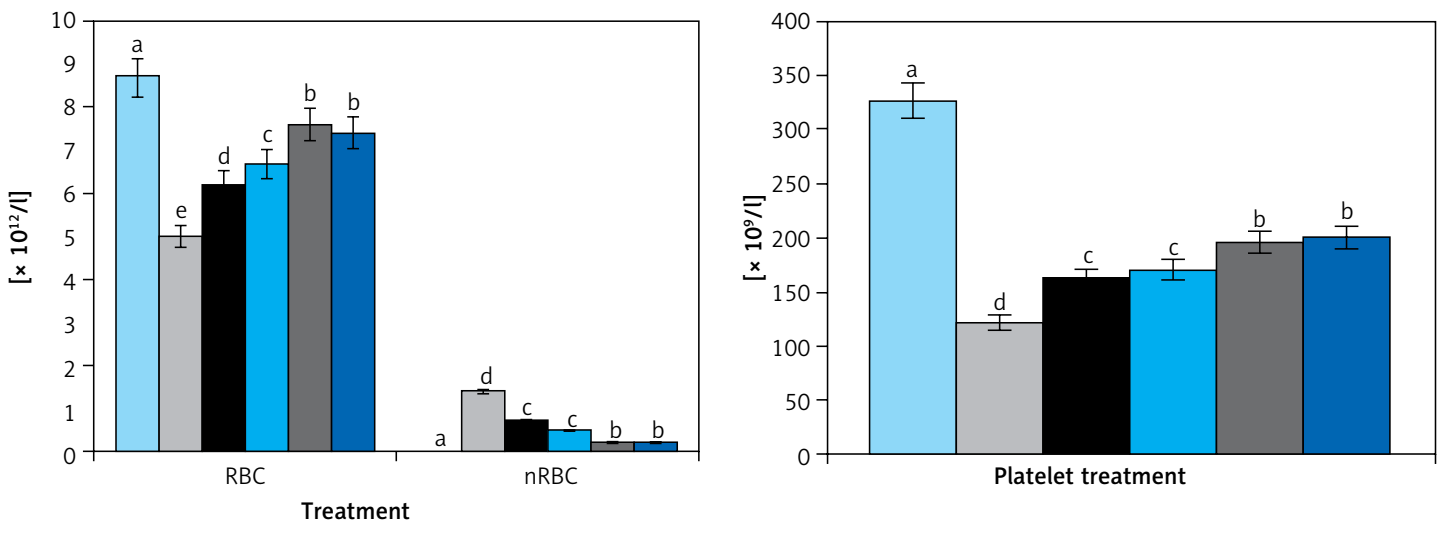

Platelet treatment

$\square$ Control $\quad \square$ Untreated

$\square$ Z. clinopodioides

$\square$ CdNPs

Daunorubicin

C

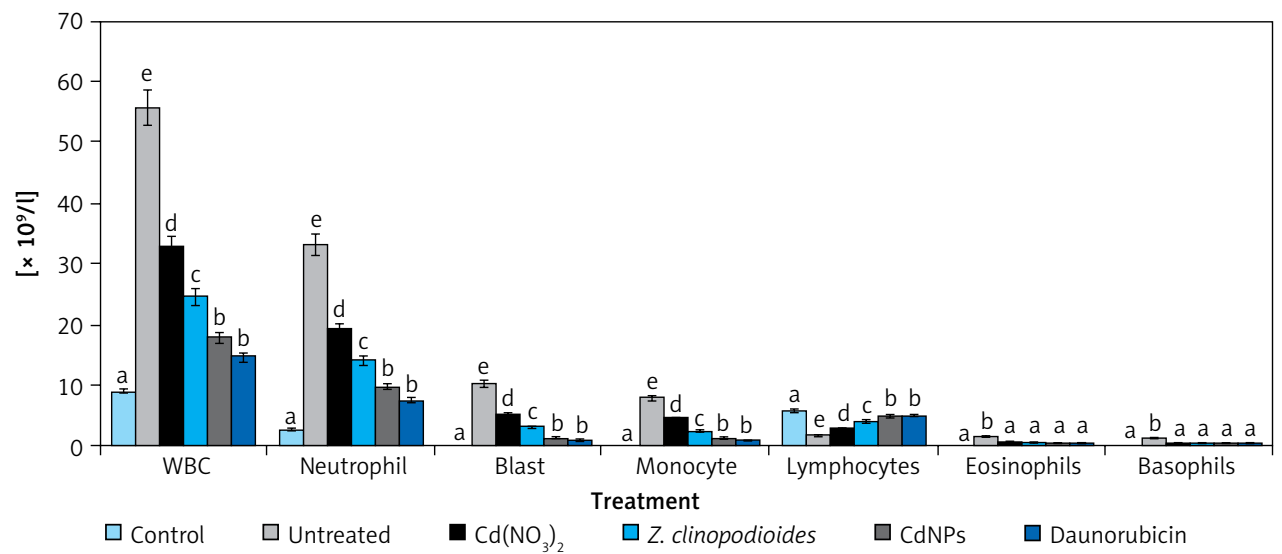

Figure 5. Numbers of platelets, RBCs, nRBCs, and WBCs in the experimental groups $(p \leq 0.01)$ 
A

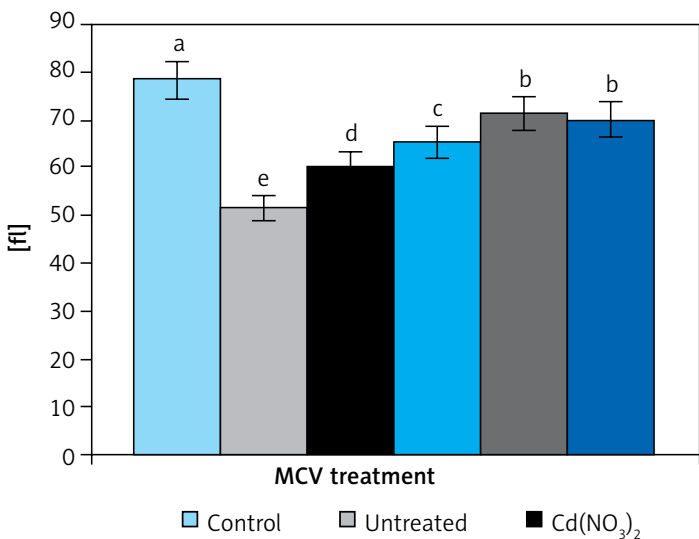

C

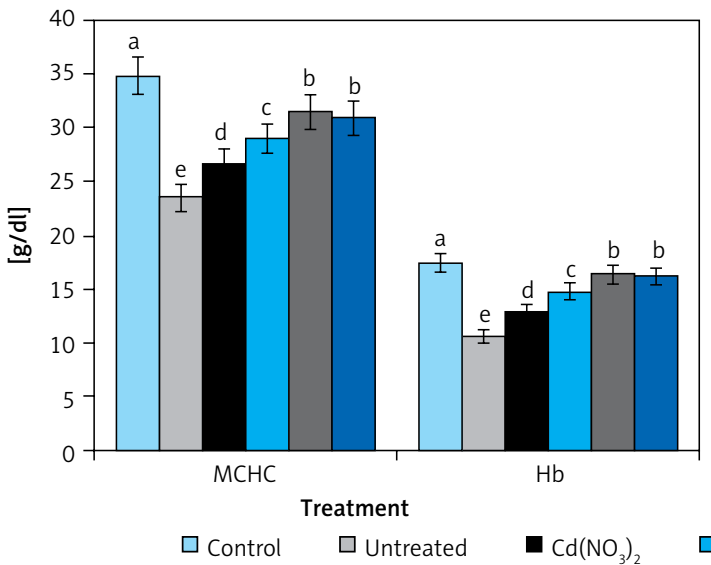

B

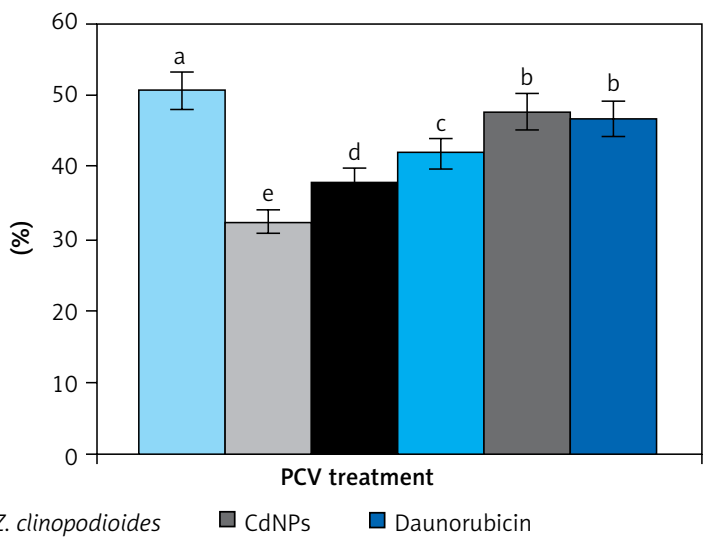

D

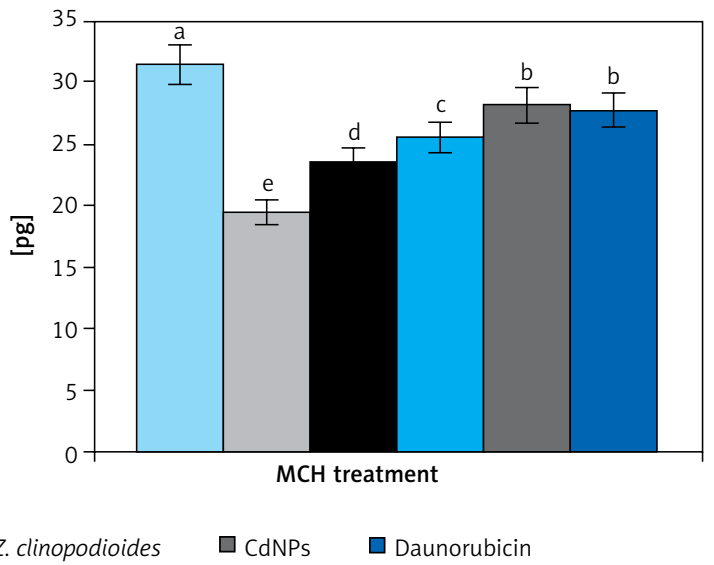

Figure 6. Levels of RBC parameters in tested groups $(p \leq 0.01)$

aqueous extract, CdNP, and daunorubicin, respectively, compared to the untreated group. Also, the findings of S1PR5 mRNA expression revealed the fold increase of 36.8, 12.1, 17.3, 24.2, and 26.9 in control, $\mathrm{Cd}\left(\mathrm{NO}_{3}\right)_{2}$, Z. clinopodioides leaf aqueous extract, CdNP, and daunorubicin, respectively, in comparison to the untreated group. The best results were seen in the daunorubicin and $\mathrm{Cd}$ NP-treated groups (Figure 7).

In this study, DMBA-induced acute myeloid leukemia significantly $(p \leq 0.01)$ increased the concentrations of ALP, AST, ALT, GGT, cholesterol, LDL, triglyceride, total and conjugated bilirubin, glucose, urea, creatinine, ferrous, ferritin, and erythropoietin and decreased HDL, total protein and albumin in serum. $\mathrm{Cd}\left(\mathrm{NO}_{3}\right)_{2}$, Z. clinopodioides leaf aqueous extract, CdNPs, and daunorubicin significantly $(p \leq$ $0.01)$ ameliorated the above parameters. There were no significant differences $(p \leq 0.01)$ between CdNP, daunorubicin, and control groups in GGT, triglyceride, glucose, and creatinine levels. The best results in improving the biochemical parameters were seen in the CdNP-treated group (Table I).

In the recent study, the levels of the liver, spleen, and serum SOD, CAT, and GPx increased and GR decreased significantly $(p \leq 0.01)$ in $\mathrm{Cd}\left(\mathrm{NO}_{3}\right)_{2}$,
Z. clinopodioides leaf aqueous extract, CdNPs, and daunorubicin-treated mice in comparison to the untreated group. In agreement with our study, the study of Saravanan and Ponmurugan (2013) revealed a strong antioxidant effect of medicinal plants with amelioration of the concentrations of SOD, CAT, and GPx [42].

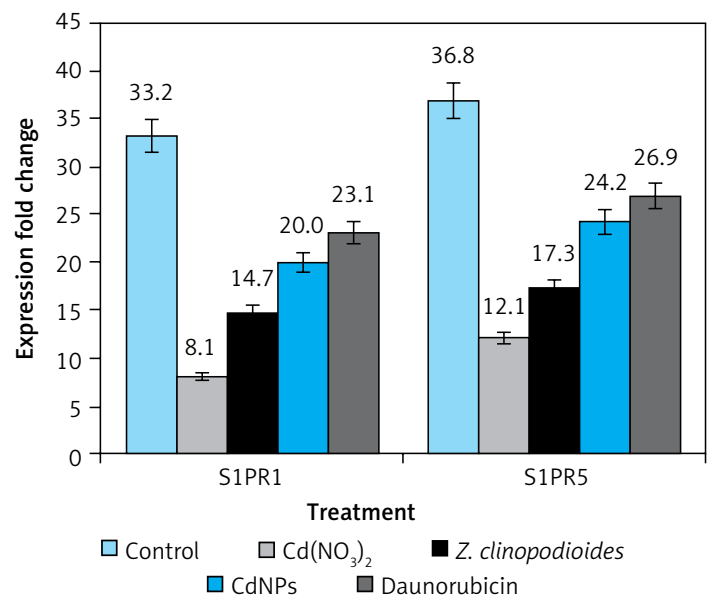

Figure 7. Expression fold change of S1PR1 and S1PR5 in control, $\mathrm{Cd}\left(\mathrm{NO}_{3}\right)_{2}$, Z. clinopodioides leaf aqueous extract, CdNPs, and daunorubicin groups in comparison to the untreated group 
Table I. Levels of biochemical parameters in tested groups $(p \leq 0.01)$

\begin{tabular}{|c|c|c|c|c|c|c|}
\hline \multirow[t]{2}{*}{ Parameter } & \multicolumn{6}{|c|}{ Groups $(n=10)$} \\
\hline & Control & Untreated & $\begin{array}{l}\text { Daunoru- } \\
\text { bicin }\end{array}$ & $\mathrm{Cd}\left(\mathrm{NO}_{3}\right)_{2}$ & $\begin{array}{l}\text { Z. clinopo- } \\
\text { dioides }\end{array}$ & CdNPs \\
\hline \multicolumn{7}{|l|}{ Serum: } \\
\hline ALP [IU/I] & $176.3 \pm 10.1^{\mathrm{a}}$ & $569.2 \pm 18.4^{d}$ & $323.6 \pm 13.2^{c}$ & $347.4 \pm 14.7^{c}$ & $317.8 \pm 15.1^{c}$ & $229.7 \pm 12.8^{b}$ \\
\hline AST [IU/I] & $99.6 \pm 8.3^{a}$ & $401.5 \pm 14.2^{c}$ & $197.8 \pm 11.4^{b}$ & $220 \pm 14.2^{b}$ & $192.4 \pm 13^{b}$ & $185.3 \pm 12.1^{\mathrm{b}}$ \\
\hline ALT [IU/I] & $31.5 \pm 2.5^{a}$ & $69.4 \pm 4.7^{d}$ & $48.6 \pm 3.9^{b}$ & $56.2 \pm 4.3^{c}$ & $46.3 \pm 3.6^{b}$ & $36.5 \pm 3^{a}$ \\
\hline GGT [IU/I] & $7.2 \pm 0.8^{a}$ & $18.6 \pm 1.2^{\mathrm{c}}$ & $8.6 \pm 0.8^{a}$ & $12.8 \pm 0.9^{b}$ & $8.5 \pm 0.7^{\mathrm{a}}$ & $8 \pm 0.9^{a}$ \\
\hline Cholesterol [mmol/l] & $4.8 \pm 0.4^{a}$ & $7.1 \pm 0.6^{\mathrm{d}}$ & $5.7 \pm 0.4^{b}$ & $6.5 \pm 0.3^{c}$ & $5.6 \pm 0.4^{b}$ & $5.5 \pm 0.3^{b}$ \\
\hline $\mathrm{LDL}[\mathrm{mmol} / \mathrm{I}]$ & $3.2 \pm 0.2^{a}$ & $5.9 \pm 0.5^{d}$ & $4.5 \pm 0.3^{b}$ & $5.2 \pm 0.2^{c}$ & $4.5 \pm 0.4^{b}$ & $4.2 \pm 0.3^{b}$ \\
\hline $\mathrm{HDL}[\mathrm{mmol} / \mathrm{l}]$ & $5.9 \pm 0.5^{a}$ & $3 \pm 0.2^{d}$ & $4.5 \pm 0.2^{b}$ & $3.8 \pm 0.3^{c}$ & $4.6 \pm 0.4^{b}$ & $5 \pm 0.3^{b}$ \\
\hline Triglyceride [mmol/l] & $0.6 \pm 0.0^{\mathrm{a}}$ & $2.2 \pm 0.1^{b}$ & $1 \pm 0.0^{\mathrm{a}}$ & $1.1 \pm 0.0^{\mathrm{a}}$ & $1 \pm 0.0^{\mathrm{a}}$ & $0.8 \pm 0.0^{\mathrm{a}}$ \\
\hline Total protein [g/dl] & $8.1 \pm 0.9^{a}$ & $4.2 \pm 0.5^{\mathrm{e}}$ & $6.3 \pm 0.6^{c}$ & $5.3 \pm 0.5^{d}$ & $6.5 \pm 0.5^{c}$ & $7.3 \pm 0.4^{b}$ \\
\hline Albumin [g/dl] & $3.2 \pm 0.2^{a}$ & $1.4 \pm 0.1^{c}$ & $2.3 \pm 0.2^{b}$ & $2 \pm 0.1^{b}$ & $2.3 \pm 0.2^{b}$ & $2.9 \pm 0.3^{a}$ \\
\hline Total bilirubin $[\mathrm{mg} / \mathrm{dl}]$ & $0.41 \pm 0.0^{a}$ & $0.86 \pm 0.0^{\mathrm{e}}$ & $0.6 \pm 0.0^{d}$ & $0.65 \pm 0.0^{c}$ & $0.6 \pm 0.0^{c}$ & $0.5 \pm 0.0^{b}$ \\
\hline Conjugated bilirubin [mg/dl] & $0.09 \pm 0.0^{a}$ & $0.23 \pm 0.0^{c}$ & $0.15 \pm 0.0^{\mathrm{b}}$ & $0.16 \pm 0.0^{b}$ & $0.14 \pm 0.0^{b}$ & $0.10 \pm 0.0^{\mathrm{a}}$ \\
\hline Glucose [g/dl] & $76.7 \pm 7.5^{a}$ & $124.3 \pm 10.7^{b}$ & $85.6 \pm 9.2^{a}$ & $88.7 \pm 10^{a}$ & $84.2 \pm 8.3^{a}$ & $80.3 \pm 8.6^{a}$ \\
\hline Urea $[\mathrm{mg} / \mathrm{dl}]$ & $12.1 \pm 0.9^{a}$ & $35.4 \pm 2.6^{d}$ & $21.4 \pm 1^{b}$ & $26.4 \pm 1.3^{c}$ & $21.7 \pm 0.9^{b}$ & $19.7 \pm 0.8^{b}$ \\
\hline Creatinine $[\mathrm{mg} / \mathrm{dl}]$ & $0.6 \pm 0.0^{\mathrm{a}}$ & $1.9 \pm 0.0^{\mathrm{b}}$ & $0.8 \pm 0.0^{\mathrm{a}}$ & $1 \pm 0.0^{a}$ & $0.8 \pm 0.0^{\mathrm{a}}$ & $0.8 \pm 0.0^{\mathrm{a}}$ \\
\hline Ferrous [ $\mu \mathrm{g} / \mathrm{dl}]$ & $196.5 \pm 11.5^{a}$ & $395.6 \pm 14.3^{d}$ & $256.6 \pm 12.5^{b}$ & $315.3 \pm 13.2^{c}$ & $300.2 \pm 12^{c}$ & $243.5 \pm 9.6^{b}$ \\
\hline Ferritin [ $\mu \mathrm{g} / \mathrm{g}$ protein] & $165.7 \pm 11.4^{a}$ & $419.6 \pm 15.2^{d}$ & $285.3 \pm 11.7^{\mathrm{b}}$ & $343.2 \pm 12.9^{c}$ & $327.6 \pm 11.2^{c}$ & $259.5 \pm 12.4^{b}$ \\
\hline Erythropoietin [mU/ml] & $18.7 \pm 1.4^{\mathrm{a}}$ & $43.7 \pm 3.2^{d}$ & $26.5 \pm 2^{b}$ & $30.5 \pm 1.6^{c}$ & $26.8 \pm 1.4^{b}$ & $24.3 \pm 1.9^{b}$ \\
\hline SOD $[\mu \mathrm{l} / \mathrm{mg}$ protein] & $9.6 \pm 0.8^{a}$ & $3.8 \pm 0.4^{\mathrm{e}}$ & $6.4 \pm 0.6^{c}$ & $5.5 \pm 0.6^{d}$ & $6.3 \pm 0.5^{c}$ & $7.3 \pm 0.7^{b}$ \\
\hline CAT $[\mu \mathrm{l} / \mathrm{mg}$ protein] & $3.1 \pm 0.3$ & $0.9 \pm 0.1^{c}$ & $2.8 \pm 0.2^{\mathrm{a}}$ & $2.3 \pm 0.1^{b}$ & $2.9 \pm 0.1^{a}$ & $3.1 \pm 0.2^{\mathrm{a}}$ \\
\hline $\mathrm{GR}[\mathrm{U} / \mathrm{ml}$ protein] & $5.4 \pm 0.4^{a}$ & $14.6 \pm 1.2^{\mathrm{e}}$ & $8 \pm 0.7^{c}$ & $10.1 \pm 0.7^{d}$ & $8.2 \pm 0.8^{c}$ & $6.6 \pm 0.3^{b}$ \\
\hline GPx [U/ml protein] & $1.8 \pm 0.1^{\mathrm{a}}$ & $0.5 \pm 0.0^{b}$ & $1.6 \pm 0.0^{a}$ & $1.5 \pm 0.0^{\mathrm{a}}$ & $1.6 \pm 0.0^{a}$ & $1.7 \pm 0.0^{\mathrm{a}}$ \\
\hline \multicolumn{7}{|l|}{ Spleen: } \\
\hline SOD $[\mu \mathrm{l} / \mathrm{mg}$ protein $]$ & $31.6 \pm 2.9^{a}$ & $9 \pm 0.8^{d}$ & $19.9 \pm 0.8^{b}$ & $14.8 \pm 0.9^{c}$ & $15.8 \pm 1.2^{c}$ & $18.7 \pm 0.7^{b}$ \\
\hline CAT [ $\mu \mathrm{l} / \mathrm{mg}$ protein] & $17.8 \pm 1.5^{a}$ & $6.7 \pm 0.8^{c}$ & $15.6 \pm 1.1^{a}$ & $11.7 \pm 0.8^{b}$ & $12.4 \pm 0.7^{b}$ & $15.2 \pm 0.9^{a}$ \\
\hline GR [U/ml protein] & $3.8 \pm 0.3^{a}$ & $15.7 \pm 0.9^{d}$ & $6.1 \pm 0.5^{b}$ & $9.8 \pm 0.7^{c}$ & $8.8 \pm 0.6^{c}$ & $6.6 \pm 0.7^{b}$ \\
\hline GPx [U/ml protein] & $1.7 \pm 0.1^{\mathrm{a}}$ & $0.3 \pm 0.0^{b}$ & $1.5 \pm 0.0^{\mathrm{a}}$ & $1.4 \pm 0.0^{\mathrm{a}}$ & $1.4 \pm 0.0^{\mathrm{a}}$ & $1.5 \pm 0.0^{\mathrm{a}}$ \\
\hline \multicolumn{7}{|l|}{ Liver: } \\
\hline SOD $[\mu \mathrm{l} / \mathrm{mg}$ protein $]$ & $44.2 \pm 3.6^{a}$ & $19.8 \pm 1.2^{d}$ & $36.2 \pm 2.3^{b}$ & $26.8 \pm 1.7^{c}$ & $28.6 \pm 1.9^{c}$ & $34 \pm 1.7^{b}$ \\
\hline CAT $[\mu \mathrm{l} / \mathrm{mg}$ protein] & $25.8 \pm 1.4^{a}$ & $8.9 \pm 0.7^{d}$ & $19.8 \pm 0.9^{b}$ & $15.1 \pm 1.1^{c}$ & $15.7 \pm 0.8^{c}$ & $19.5 \pm 1^{b}$ \\
\hline $\mathrm{GR}[\mathrm{U} / \mathrm{ml}$ protein $]$ & $7.1 \pm 0.7^{a}$ & $20.4 \pm 1.5^{\mathrm{e}}$ & $9.2 \pm 1^{b}$ & $14.2 \pm 1.1^{\mathrm{d}}$ & $14 \pm 0.9^{d}$ & $11.3 \pm 0.7^{c}$ \\
\hline GPx [U/ml protein] & $2.2 \pm 0.2^{\mathrm{a}}$ & $0.8 \pm 0.0^{b}$ & $2.1 \pm 0.1^{a}$ & $1.8 \pm 0.1^{\mathrm{a}}$ & $1.8 \pm 0.1^{\mathrm{a}}$ & $2 \pm 0.1^{a}$ \\
\hline
\end{tabular}

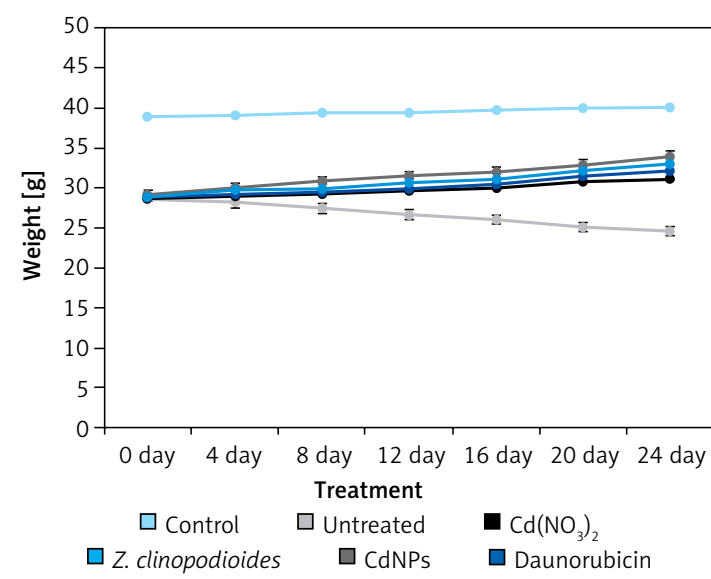

Figure 8. Weights of the body in tested groups
In the present study, the body weight of the untreated group decreased $(p \leq 0.01)$ after 6 weeks of acute myeloid leukemia induction.

Cancer cachexia is a wasting syndrome involving loss of muscle mass and fat directly caused by tumor factors [43--47]. But, the administration of $\mathrm{Cd}\left(\mathrm{NO}_{3}\right)_{2}, Z$. clinopodioides leaf aqueous extract, CdNPs, and daunorubicin raised ( $p \leq 0.01)$ the body weight in comparison to the untreated group (Figure 8).

The results analysis of Figures 9-11 indicated that DMBA significantly $(p \leq 0.01)$ increased the leukemic myeloblasts infiltrating the spleen and liver. With this infiltration, the volumes and weights of spleen and liver and their sub-com- 
partments rose in the untreated as compared to other groups.

In detail, DMBA significantly increased $(p \leq$ 0.01 ) the volumes of hepatocytes, central vein, portal vein, sinusoid, bile duct, and hepatic artery in the liver and the volumes of white pulp, marginal zone, and follicle in the spleen.

Treatment with $\mathrm{Cd}\left(\mathrm{NO}_{3}\right)_{2}$, Z. clinopodioides leaf aqueous extract, CdNPs, and daunorubicin significantly reduced $(p \leq 0.01)$ the leukemic myeloblasts infiltrating the liver and spleen. The best results were observed in the CdNP and daunorubicin-treated groups.

\section{Characterization of CdNPs}

Using EDS (Figure 12), the elemental composition profile of the biosynthetic CdNPs showed the presence of cadmium biosynthesized NPs considering the signals appearing at 3.16 and $3.34 \mathrm{keV}$ corresponded to the $L \alpha$ and $L \beta$ peaks of cadmium while the peaks at around 2.3-2.5 keV corresponded to the $K \alpha$ and $K \beta$ peaks of sulfur. These signals also match those of a previous study on the $\mathrm{Cd}$ NPs synthesized using $C$. reinhardtii extract [48]; The other signals including $\mathrm{Ok} \alpha$ and $\mathrm{CK} \alpha$ belong to the organic molecules present in Z $Z$. clinopodioides extract that linked to the surface of CdNPs.

Figure 13 shows the XRD pattern of the biosynthesized CdNPs which demonstrates the synthesis of cadmium sulfide. The peaks at $2 \theta$ values of $26.68,44.16,52.47$, and 70.65 are indexed as (111), (202), (311), and (313) planes, which are in good agreement with those of clinic phase CdS obtained from standard database ICDD PDF card no. 96-900-0068. The crystallinity of the sample was accepted using the XRD diffractogram. The purity of the sample is proved because of the absence of unmatched peaks. Peaks at different degrees have also been reported previously [48-55].

The CdNP nanoparticles had an average crystal size of $25.65 \mathrm{~nm}$ that was calculated using the $X$ Scherrer equation: $D=(k \lambda / \beta \cos \theta)$.

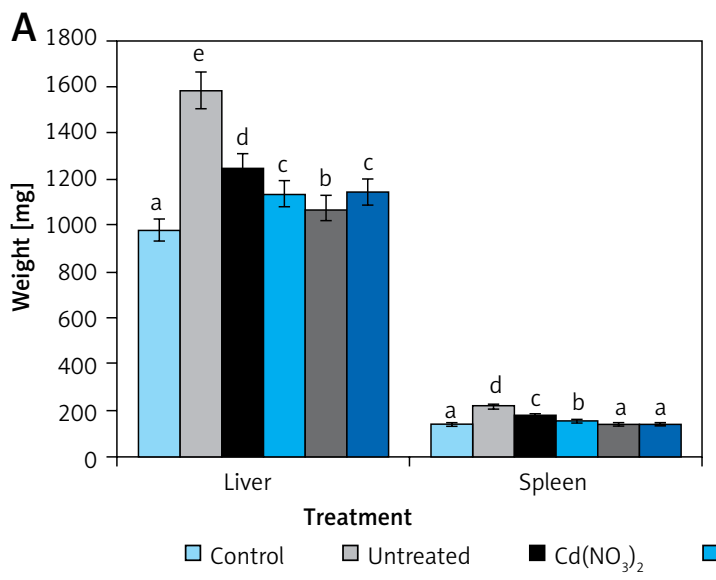

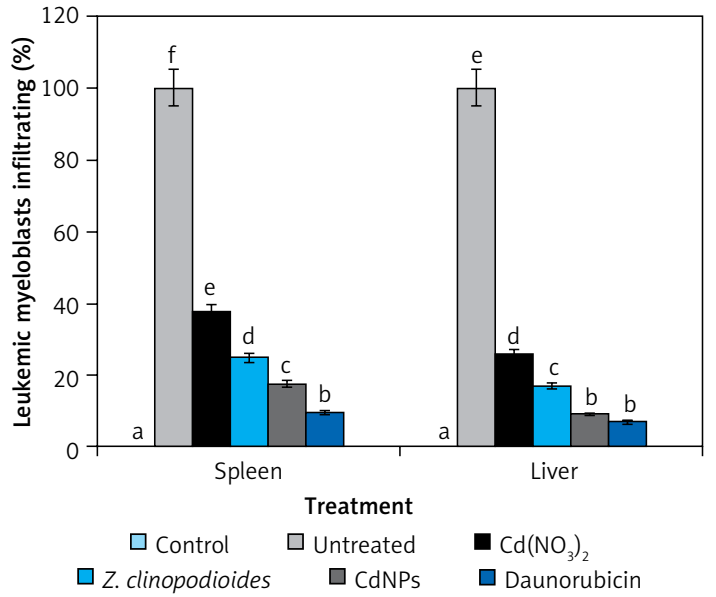

Figure 9. Percentage of leukemic myeloblasts infiltrating spleen and liver in tested groups $(p \leq 0.01)$

In our literature review, cadmium sulfide and cadmium oxide are the common products of the biosynthesis of cadmium nanoparticles. The studies have reported various crystal sizes for the biosynthetic CdSNPs or CdONPs according to the XRD patterns. For CdSNPs the crystal size of $3.42 \mathrm{~nm}$ has been reported for the synthetic CdSNPs using Annona muricata leaf extract [23]; $6 \mathrm{~nm}$ for Chlamydomonas reinhardtii [48]; $1.47 \mathrm{~nm}$ for banana peel extract [49]; $18 \mathrm{~nm}$ and $12 \mathrm{~nm}$ for Calotropis gigantea leaf extract [51]; $5.67 \mathrm{~nm}$ for Mimosa pudica [52-55]; $4 \mathrm{~nm}$ for Murraya koenigii extract [56]. On the other hand, $10.86 \mathrm{~nm}$ has been reported for the synthetic CdONPs using Limonia acidissima leaf extract [57]; 18.5-61.9 nm for Abelmoschus esculentus [58]; $22 \mathrm{~nm}$ for Andrographis paniculata leaf extract [59]; 25 to $50 \mathrm{~nm}$ for Agathosma betulina [60]; 22.9 and $35.0 \mathrm{~nm}$ for Hibiscus sabdariffa flower extract [61]; 44-56 nm for Aloe barbadensis [62]; 28.92 to $44.95 \mathrm{~nm}$ for Parkia speciosa seed extract [63].

FT-IR (Fourier transform infrared) is a suitable technique for analyzing materials in the laboratory. An infrared spectrum represents the fingerprint of the sample under test with absorption peaks,

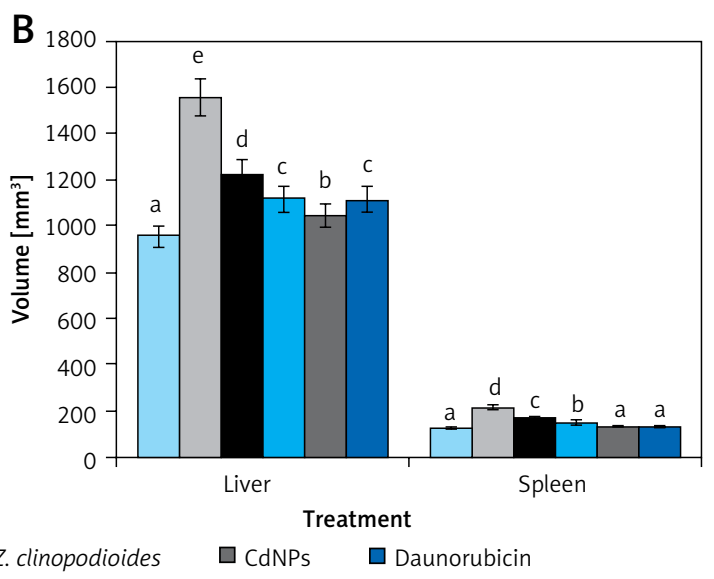

Figure 10. Weights (A) and volumes (B) of liver and spleen in tested groups $(p \leq 0.01)$ 
A

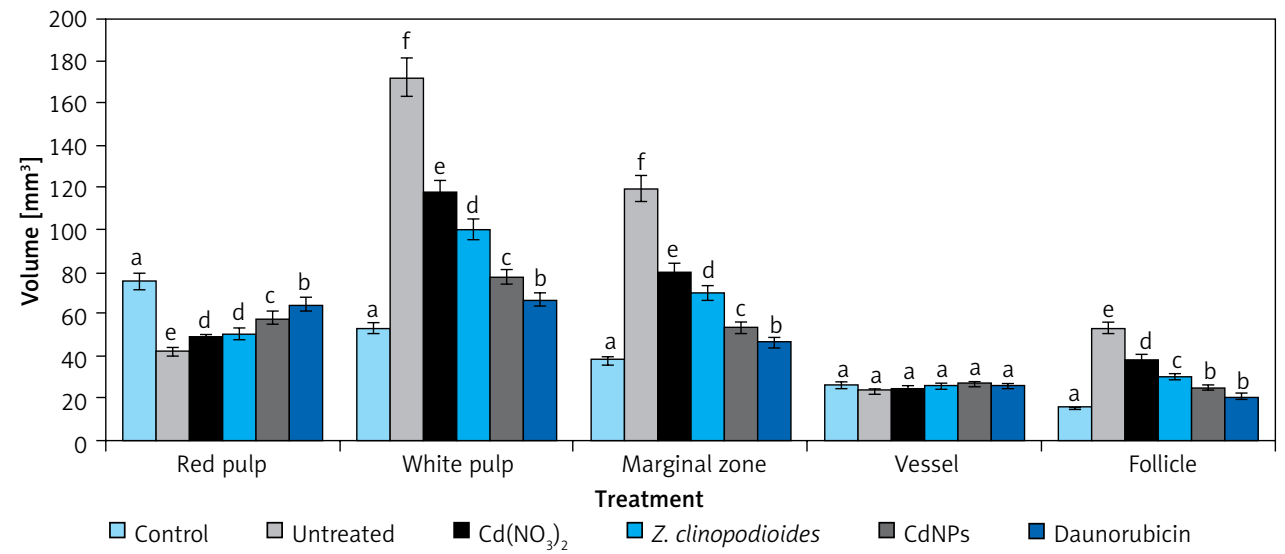

B

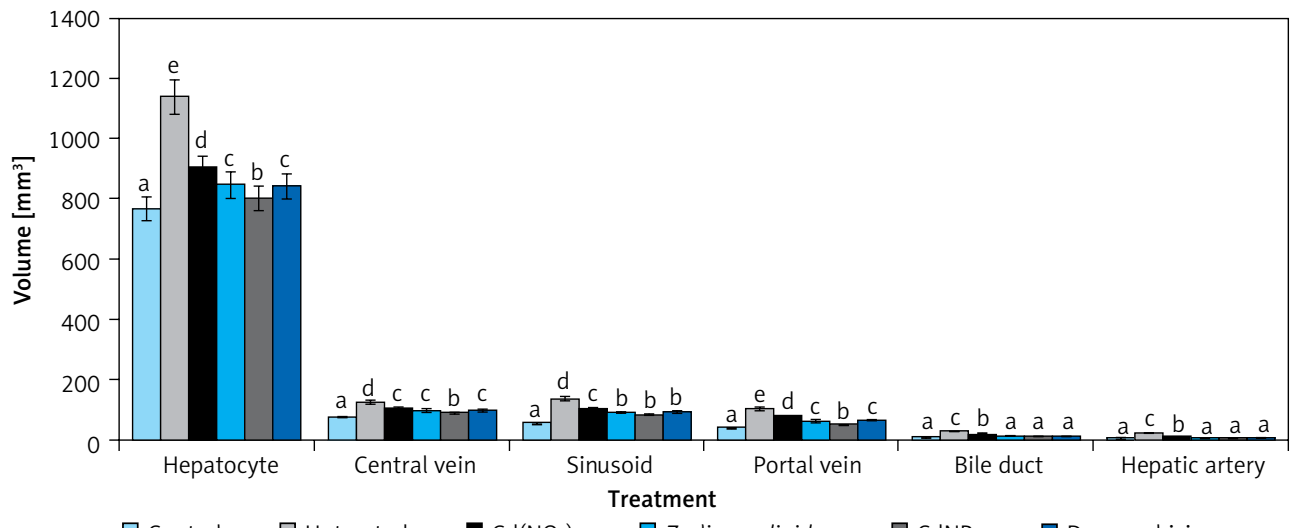

$$
\square \text { Control } \quad \square \text { Untreated } \quad \square \mathrm{Cd}\left(\mathrm{NO}_{3}\right)_{2} \quad \square \text { Z. clinopodioides } \quad \square \text { CdNPs } \quad \square \text { Daunorubicin }
$$

Figure 11. Levels of stereological parameters of liver and spleen in tested groups $(p \leq 0.01)$. A - Spleen. B - Liver

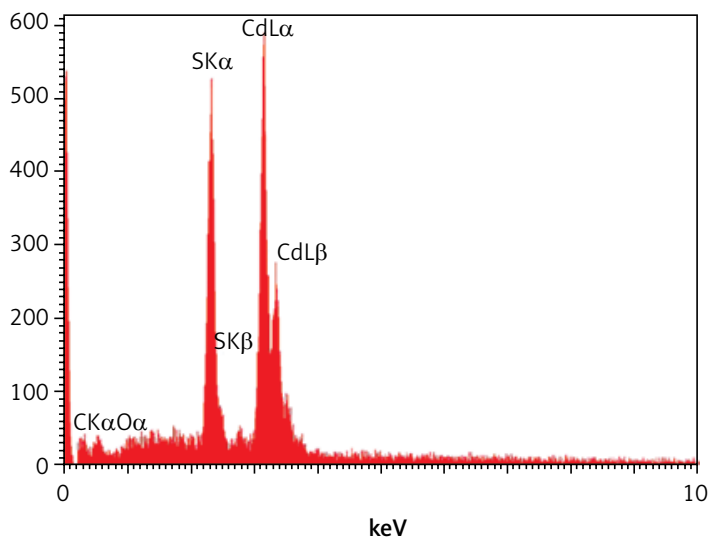

\section{Element}

Weight (\%)

\begin{tabular}{|l|c|c|}
\hline C & 11.78 & 41.16 \\
\hline O & 4.08 & 10.70 \\
\hline S & 17.86 & 23.39 \\
\hline Cd & 66.28 & 24.76 \\
\hline & 100.00 & 100.00 \\
\hline
\end{tabular}

Figure 12. EDS pattern of CdNPs

which depends on the vibrational frequencies between the atomic bonds of that material. Since each substance has its own atomic bonds, no two compounds with the same infrared spectrum are alike. Hence, infrared spectroscopy can be effec-

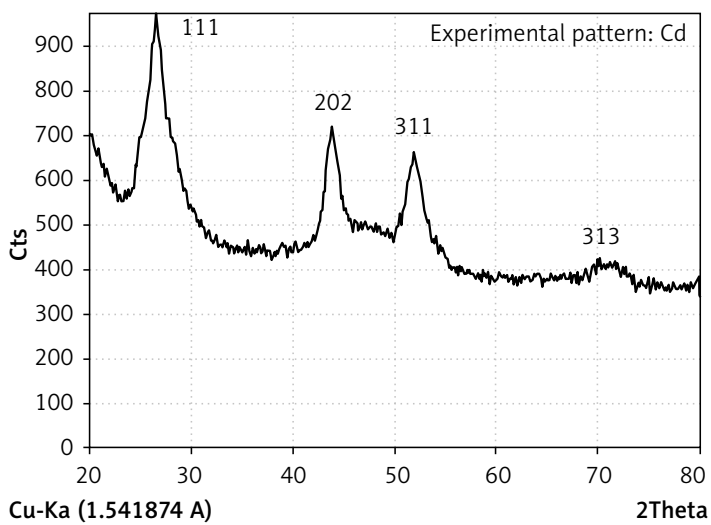

Figure 13. XRD data of CdNPs

tive in better identification (qualitative analysis) of different types of materials. Also, the peak sizes are in the range indicating the amount of material present. Advanced software algorithms make this spectroscopy a great tool for quantitative analysis [48, 51, 52].

In FT-IR spectra of metal oxides, the vibration band for the metal-oxygen bond usually appears at 500 to $700 \mathrm{~cm}^{-1}$. Figure 14 presents the spectra of CdNPs. The peaks at 524, 621, and $678 \mathrm{~cm}^{-1}$ are attributed to the bending vibration of $\mathrm{Cd}$-S. These peaks for biosynthetic CdNPs have been reported 
previously with a small difference in the respective wavenumber [48, 51, 52]. FT-IR spectroscopy is a reliable strategy to evaluate the secondary plant metabolites as the capping and reducing agents of $\mathrm{Cd}\left(\mathrm{NO}_{3}\right)_{2}$ precursor to CdNPs. According to the findings of this report, the FT-IR spectra of CdNPs and Z. clinopodioides extract were very similar to each other, confirming the successful biosynthesis of the cadmium nanoparticles. The presence of different IR bands correlates with the existence of various functional groups in $Z$. clinopodioides extract. For instance, the peaks at 3371 and $2939 \mathrm{~cm}^{-1}$ for $\mathrm{O}-\mathrm{H}$ and aliphatic $\mathrm{C}-\mathrm{H}$ stretching, the bands in the range of 1421 to $1749 \mathrm{~cm}^{-1}$ for $\mathrm{C}=\mathrm{C}$ and $\mathrm{C}=\mathrm{O}$ stretching, and the peaks at 1261 and $1081 \mathrm{~cm}^{-1}$ for $-\mathrm{C}-\mathrm{O}$ and -C-O-C stretching can generally be considered to confirm the presence of various valuable natural compounds such as phenolic, flavonoid, and carboxylic compounds as secondary metabolites in Z. clinopodioides, which have been reported previously $[53,54]$. These compounds bind to metallic NPs via hydroxyl and carbonyl functional groups as the main stimulus to reduce, stabilize, and disperse metallic nanoparticles [55].

The FE-SEM device is one of the most powerful tools used in various fields, including nano-
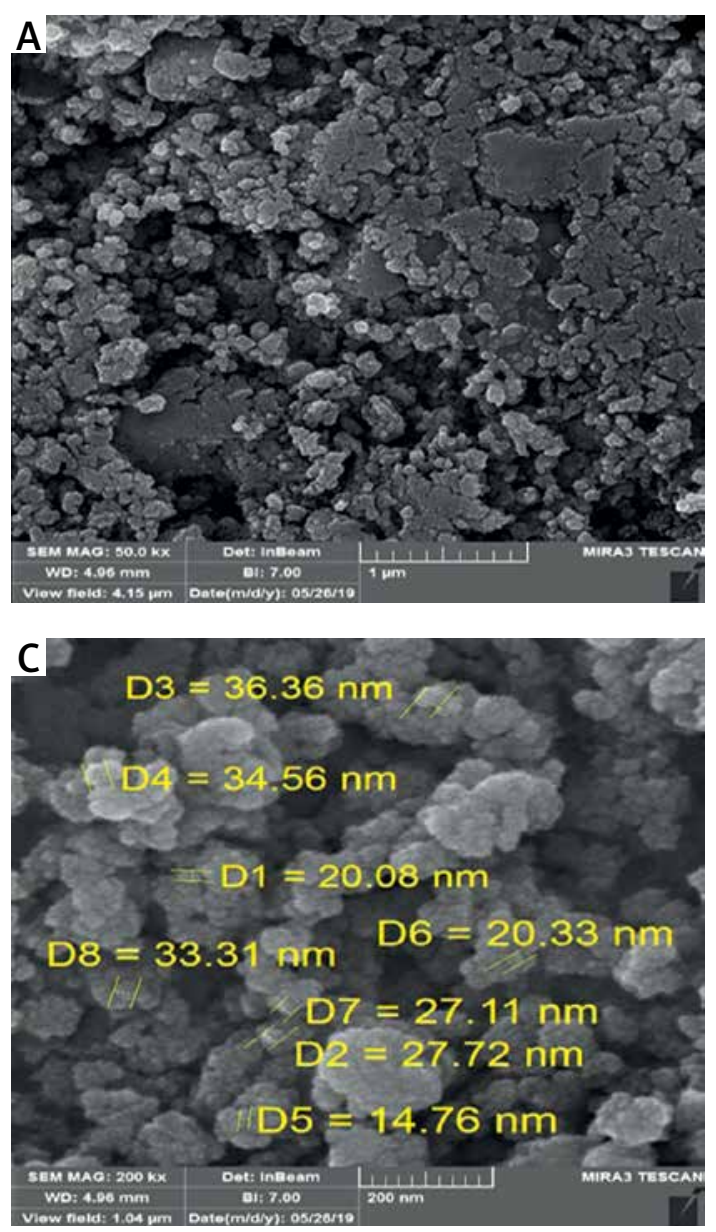
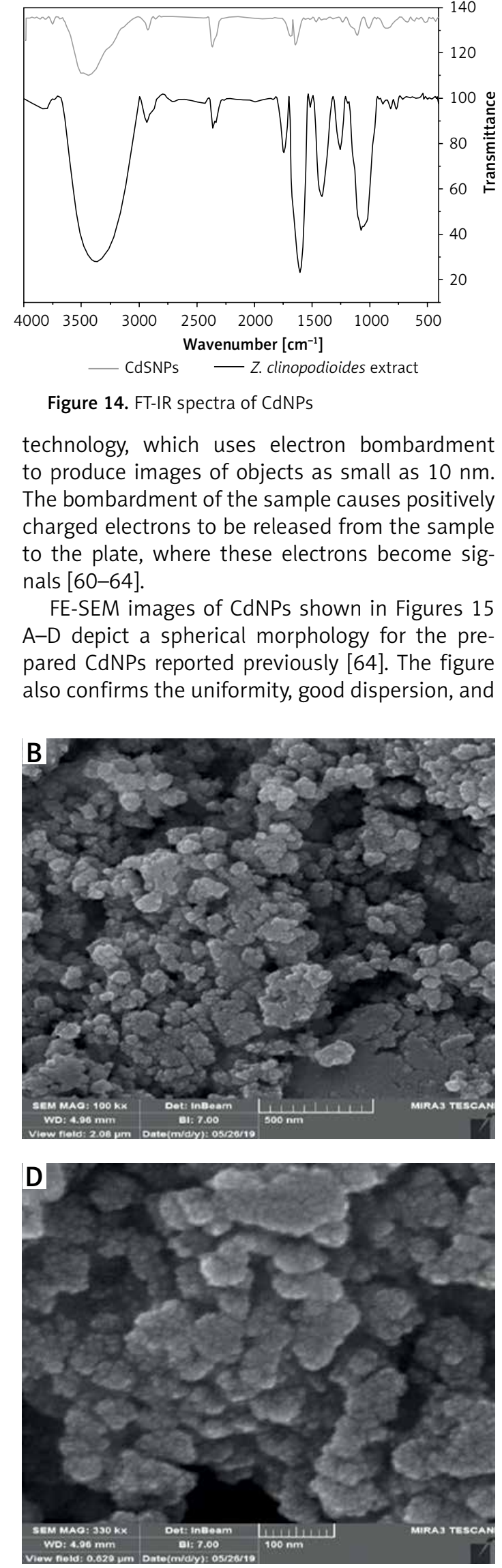

Figure 14. FT-IR spectra of CdNPs

technology, which uses electron bombardment to produce images of objects as small as $10 \mathrm{~nm}$. The bombardment of the sample causes positively charged electrons to be released from the sample to the plate, where these electrons become signals [60-64].

FE-SEM images of CdNPs shown in Figures 15 A-D depict a spherical morphology for the prepared CdNPs reported previously [64]. The figure also confirms the uniformity, good dispersion, and

Figure 15. FE-SEM image of CdNPS 


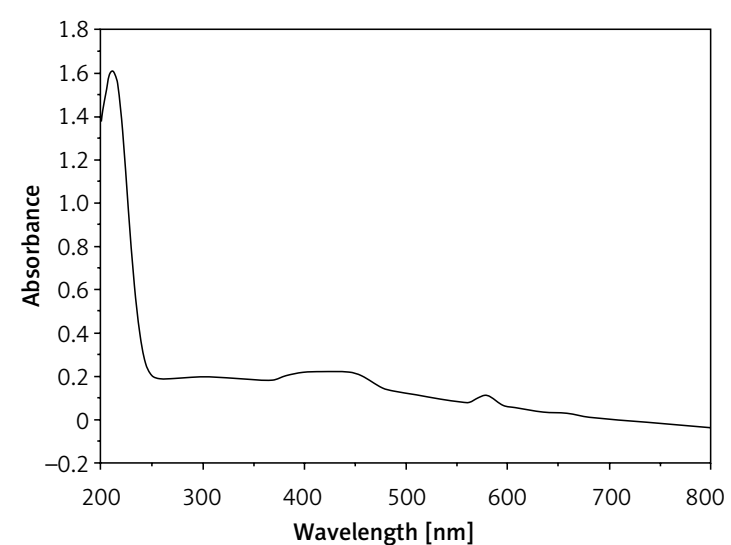

Figure 16. UV-Vis. absorption spectra of CdNPs

homogeneity of the CdNPs. Similar to the other metallic nanoparticles being synthesized using green chemistry approaches, a tendency to aggregate is observed for CdNPs. This property has been reported for other types of biosynthesized nanoparticles, viz. CdNPs, CuNPs, AgNPs, and TiNPs $[48,55,65,66]$. On average, the diameter of particle size for CdNPs was $26.78 \mathrm{~nm}$. The size is very close to the one obtained from the XRD pattern. In our review of the literature, different sizes have been reported for the biosynthesized CdSNPs or CdONPs using herbal extracts. For example, 3 to $5 \mathrm{~nm}$ has been reported for synthetic CdSNPs using tea leaf extract [64]; $4 \mathrm{~nm}$ for A. muricata [23]; 2-7 $\mathrm{nm}$ for $C$. reinhardtii [48]; $1.48 \mathrm{~nm}$ for banana peel extract [49]; 5-20 nm for fungus of Fusarium oxysporum [50]; $20 \mathrm{~nm}$ for C. gigantea leaf extract [51]; and $20 \mathrm{~nm}$ for M. koenigii [56]. On the other hand, bigger sizes have been reported for biosynthetic CdONPs: 10-30 nm for Limonia acidissima leaf extract [57]; $78 \mathrm{~nm}$ for $A$. esculentus fruit extract [58]; $164 \mathrm{~nm}$ for $A$. paniculata leaf extract [59]; $100 \mathrm{~nm}$ for A. betulina [60]; $113 \mathrm{~nm}$ for $H$. Sabdariffa flower extract [61]; 97-129 nm for A. Barbadensis [62]; 20-50 nm for P. speciosa seed extract [63]; and 36-57nm for Leucaena leucocephala [67].

UV-Vis. is based on the irradiation of ultraviolet and visible photons on the sample and measures the rate of passage or absorption of matter at different wavelengths in the range of 200 to $1100 \mathrm{~nm}$. It is possible to measure the spectrum for samples in solution, solid as well as thin layers. The size of solid samples should be larger than $20 \mathrm{~mm}$. This test is not possible for powder samples. One of the important applications of the UV device is to determine the concentration of the unknown solution. By having the original sample and its solvent and making several solutions with different percentages and drawing a calibration diagram based on the calculation of the maximum land, the concentration of the unknown solutions can be calculated [50-53].
The UV-Vis. spectrum of biosynthesized CdNPs is shown in Figure 16. The surface plasmon resonance of CdNPs was confirmed by UV-Vis. and compared with a previous report; the appearance of three bands at 393, 450, and $578 \mathrm{~nm}$ confirmed the formation of CdNPs. However, in comparison with bulk absorption, a blue shift is observed in the spectrum. According to the previous studies, the decrease in the particle size is the main reason for this observation $[48,49]$. This band is also characteristic of CdS particles in the quantum size range [50].

In conclusion, in the present experiment, Z. clinopodioides extract-based cadmium nanoparticles (CdNPs) were successfully synthesized. The NPs has been completely characterized using UV-Vis. and FT-IR spectroscopy; XRD, FE-SEM, and EDS. In vivo, CdNPs significantly $(p \leq 0.01)$ regulated the levels of biochemical, immunological, hematological, histopathological, and cellular-molecular parameters similarly to daunorubicin. In vitro, CdNPs had low cell viability dose-dependently against human HL-60/vcr, 32D-FLT3-ITD, and murine C1498 cell lines without any cytotoxicity on the HUVEC cell line. According to the above results, it appears that CdNPs may be applied to treat acute myeloid leukemia in humans.

\section{Conflict of interest}

The authors declare no conflict of interest.

\section{References}

1. Raut RW, Kolekar NS, Lakkakula JR, et al. Extracellular synthesis of silver nanoparticles using dried leaves of Pongamia pinnata (L) pierre. NanoMicro Lett 2010; 2: 106-13.

2. Varma RS. Greener approach to nanomaterials and their sustainable applications. Curr Opin Chem Eng 2012; 1: 123-8.

3. Arunachalam KD, Annamalai SK, Hari S. One-step green synthesis and characterization of leaf extract-mediated biocompatible silver and gold nanoparticles from Memecylon umbellatum. Int J Nanomedicine 2003; 8: 1307-15.

4. Sintubin L, De Windt W, Dick J, et al. Lactic acid bacteria as reducing and capping agent for the fast and efficient production of silver nanoparticles. Appl Microbiol Biotechnol 2009; 84: 741-9.

5. Ball V. Polydopamine nanomaterials: recent advances in synthesis methods and applications. Front Bioeng Biotechnol 2018; 6: 109.

6. Jalalvand AR, Zhaleh M, Goorani S, et al. Chemical characterization and antioxidant, cytotoxic, antibacterial, and antifungal properties of ethanolic extract of Allium Saralicum RM Fritsch leaves rich in linolenic acid, methyl ester. J Photochem Photobiol B 2019; 192: 103-12.

7. Singh P, Pandit S, Mokkapati VR, et al. Gold nanoparticles in diagnostics and therapeutics for human cancer. Int J Mol Sci 2018; 19: 1979.

8. Hemmati S, Joshani Z, Zangeneh A, et al. Biosynthesis and chemical characterization of polydopamine-capped silver nanoparticles for the treatment of acute myeloid 
leukemia in comparison to doxorubicin in a leukemic mouse model. Appl Organometal Chem 2019; 34: e5277.

9. Zangeneh MM. Green synthesis and formulation a modern chemotherapeutic drug of Spinacia oleracea L. leaf aqueous extract conjugated silver nanoparticles: chemical characterization and analysis of their cytotoxicity, antioxidant, and anti-acute myeloid leukemia properties in comparison to doxorubicin in a leukemic mouse model. Appl Organometal Chem 2020; 34: e5295.

10. Hossain ST, Mukherjee SK. Toxicity of cadmium sulfide (CdS) nanoparticles against Escherichia coli and HeLa cells. J Hazard Mater 2013; 260: 1073-82.

11. Heidari A. A novel and modern experimental imaging and spectroscopy comparative study on malignant and benign human cancer cells and tissues with the passage of time under white synchrotron radiation. Cancer Sci Res Open Access 2017; 4: 1-8.

12. Soni A, Krishnamurthy R. Plants-the next generation treatment of leukemia. Indian J Plant Sci 2013; 2: 117-25.

13. Hagh-Nazari L, Goodarzi N, Zangeneh MM, et al. Stereological study of kidney in streptozotocin-induced diabetic mice treated with ethanolic extract of Stevia rebaudiana (bitter fraction). Comp Clin Pathol 2017; 26: 455-63.

14. Zangeneh MM, Zangeneh A, Pirabbasi E, et al. Falcaria vulgaris leaf aqueous extract mediated synthesis of iron nanoparticles and their therapeutic potentials under in vitro and in vivo condition. Appl Organometal Chem 2019; 33: e5246.

15. Naghibi F, Mosadegh M, Mohammadi MS, et al. Labiatae family in folk medicine in Iran: from ethnobotany to pharmacology. Iran J Pharm Res 2005; 4: 63-79.

16. Behravan J, Ramezani M, Hassanzadeh MK, et al. Composition, antimycotic and antibacterial activity of Ziziphora clinopodioides Lam. essential oil from Iran. J Essent Oil Bear 2007; 10: 339-45.

17. Sonboli A, Mirjalili MH, Hadian J, et al. Antibacterial activity and composition of the essential oil of Ziziphora clinopodioides subsp. bungeana (Juz.) Rech. f. from Iran. Zeit Natur C 2006; 61: 677-80.

18. Salehi P, Sonboli A, Eftekhar F, et al. Essential oil composition, antibacterial and antioxidant activity of the oil and various extracts of Ziziphora clinopodioides subsp. rigida (B OISS.) R ECH. f. from Iran. Biol Pharm Bull 2005; 28: 1892-6.

19. Ghafari H, Yasa N, Mohammadirad A, et al. Protection by Ziziphora clinopoides of acetic acid-induced toxic bowel inflammation through reduction of cellular lipid peroxidation and myeloperoxidase activity. Hum Exp Toxicol 2006; 25: 325-32.

20. Meral GE, Konyalioglu S, Ozturk B. Essential oil composition and antioxidant activity of endemic Ziziphora taurica subsp. cleonioides. Fitoterapia 2002; 73: 716-8.

21. Mahdavi B, Paydarfard S, Zangeneh MM, et al. Assessment of antioxidant, cytotoxicity, antibacterial, antifungal, and cutaneous wound healing activities of green synthesized manganese nanoparticles using Ziziphora clinopodioides Lam leaves under in vitro and in vivo condition. Appl Organometal Chem 2020; 34: e5248.

22. Belyaev NF, Demeubaeva AM. Chromatographic study of the composition of the essential oil of Ziziphora clinopodioides, a vicarious form of Origanum vulgare. Chem Nat Compd 1999; 35: 52-4.

23. Durga B, Raziya S, Rajmahanti SG, et al. Synthesis and characterization of cadmium sulphide nanoparticles using annona muricata leaf extract as reducing/capping agent. Chem Sci Trans 2016; 5: 1035-41.
24. Sánchez-Moreno C, Larrauri JA, Saura-Calixto F. A procedure to measure the antiradical efficiency of polyphenols. J Sci Food Agric 1998; 76: 270-6.

25. Arulmozhi V, Pandian K, Mirunalini S. Ellagic acid encapsulated chitosan nanoparticles for drug delivery system in human oral cancer cell line (KB). Colloids Surf B Biointerfaces 2013; 110: 313-20.

26. Kabeel MM, Ghoneim AM, Mansy SE. Anti-leukemic activity of a four-plant mixture in a leukemic rat model. J Basic Appl Zool 2018; 79: 7.

27. Martin Jr JP, Dailey M, Sugarman E. Negative and positive assays of superoxide dismutase based on hematoxylin autoxidation. Arch Biochem Biophys 1987; 255: 329-36.

28. Ho YS, Magnenat JL, Bronson RT, et al. Ice deficient in cellular glutathione peroxidase develop normally and show no increased sensitivity to hyperoxia. J Biol Chem 1997; 272: 16644-51.

29. Namvar F, Rahman HS, Mohamad R, et al. Cytotoxic effect of magnetic iron oxide nanoparticles synthesized via seaweed aqueous extract. Int J Nanomedicine 2014; 19: 2479-88.

30. Kalita P, Tapan BK, Pal TK, et al. Estimation of total flavonoids content (TFC) and antioxidant activities of methanolic whole plant extract of Biophytum sensitivum Linn. J Drug Deliv Therap 2013; 3: 33-7.

31. Kedare SB, Singh RP. Genesis and development of DPPH method of antioxidant assay. J Food Sci Technol 2011; 48: 412-22.

32. Matthäus B. Antioxidant activity of extracts obtained from residues of different oilseeds. J Agric Food Chem 2002; 50: 3444-52.

33. Aliev G, Palacios HH, Lipsitt AE, et al. Nitric oxide as an initiator of brain lesions during the development of Alzheimer disease. Neurotox Res 2009; 16: 293-305.

34. Ishino K, Wakita C, Shibata et al. Lipid peroxidation generates body odor component trans-2-nonenal covalently bound to protein in vivo. J Biol Chem 2010; 285: 15302-13.

35. Nishimura $\mathrm{H}$, Akiyama T, Monobe $\mathrm{Y}$, et al. Expression of sphingosine-1-phosphate receptor 1 in mantle cell lymphoma. Modern Pathol 2010; 23: 439-49.

36. Abdalla DR, Aleixo AAR, Murta EFC, Michelin M. Innate immune response adaptation in mice subjected to administration of DMBA and physical activity. Oncol Lett 2014; 7: 886-90.

37. Yusuf N, Nasti TH, Meleth S, et al. Resveratrol enhances cell-mediated immune response to DMBA through TLR4 and prevents DMBA induced cutaneous carcinogenesis. Mol Carcinog 2009; 48: 713-23.

38. Sugiyama T, Osaka M, Koami K, Maeda S, Ueda N. 7,12-DMBA-induced rat leukemia: a review with insights into future research. Leuk Res 2002; 26: 1053-68.

39. Korotkova El, Misini B, Dorozhko EV, et al. Study of OH. radicals in human serum blood of healthy individuals and those with pathological schizophrenia. Int J Mol Sci 2011; 12: 401-9.

40. Teselkin JO, Babenkova IV, Lyubitsky OB, et al. Inhibition of luminol oxidation by serum antioxidants in presence of hydrogen peroxide and hemoglobin. Problems Med Chem 1997; 43: 87-93.

41. Kluk MJ, Ryan KP, Wang B, et al. Sphingosine-1-phosphate receptor 1 in classical Hodgkin lymphoma: assessment of expression and role in cell migration. Lab Invest 2013; 93: 462-71.

42. Saravanan G, Ponmurugan P. S-allylcysteine improves streptozotocin-induced alterations of blood glucose, liver cytochrome P450 2E1, plasma antioxidant system, 
and adipocytes hormones in diabetic rats. Int J Endocrinol Metab Disord 2013; 11: e10927.

43. Hoseinpouran M, Khaki A, Nazem H. Assessment of antioxidant properties of allium cepa on serum antioxidants and spermatogenesis after consuming tartrazine in rat. Crescent J Med Biol Sci 2015; 2: 125-9.

44. Ogunlade B, Saalu LC, Ogunmodede OS, et al. The salutary role of Allium cepa extract on the liver histology, liver oxidative status and liver marker enzymes of rabbits submitted to alcohol-induced toxicity. Am J Biochem Mol Biol 2012; 2: 67-81.

45. Argilés JM, Busquets S, Stemmler B, et al. Cancer cachexia: understanding the molecular basis. Nat Rev Cancer 2014; 14: 754-62.

46. Goodarzi N, Zangeneh MM, Zangeneh X, et al. Protective effects of ethanolic extract of Allium Saralicum RM Fritsch on CCl4-induced hepatotoxicity in mice. J Rafsanjan Univ Med Sci 2017; 16: 227-38.

47. Hagh-Nazari L, Goodarzi N, Zangeneh MM, et al. Stereological study of kidney in streptozotocin-induced diabetic mice treated with ethanolic extract of Stevia rebaudiana (bitter fraction). Sci Res J Shahed Univ 2018; 25: 21-30.

48. Rao MD, Pennathur G. Green synthesis and characterization of cadmium sulphide nanoparticles from Chlamydomonas reinhardtii and their application as photocatalysts. Mater Res Bull 2017; 85: 64-73.

49. Zhou GJ, Li SH, Zhang YC, Fu YZ. Biosynthesis of CdS nanoparticles in banana peel extract. J Nanosci Nanotechnol 2014; 14: 4437-42.

50. Ahmad A, Mukherjee P, Mandal D, et al. Enzyme mediated extracellular synthesis of CdS nanoparticles by the fungus, Fusarium oxysporum. J Am Chem Soc 2002; 124: 12108-9.

51. Ayodhya D, Veerabhadram G. One-pot green synthesis, characterization, photocatalytic, sensing and antimicrobial studies of Calotropis gigantea leaf extract capped CdS NPs. Mater Sci Eng B 2017; 225: 33-44.

52. Durga B, Raziya S, Rajmahanti SG, et al. Synthesis and characterization of cadmium sulphide nanoparticles using annona muricata leaf extract as reducing/capping agent. Res J Pharm Biol Chem Sci 2017; 5: 1035-41.

53. Oganesvan GB, Galstyan AM, Mnatsakanyan VA, et al. Phenolic and flavonoid compounds of Ziziphora clinopodioides. Chem Nat 1991; 27: 247-7.

54. Tian S, Shi Y, Yu Q, et al. Determination of oleanolic acid and ursolic acid contents in Ziziphora clinopodioides Lam. by HPLC method. Pharmacog Mag 2010; 6: 116-9.

55. Ghidan AY, Al-Antary TM, Awwad AM. Green synthesis of copper oxide nanoparticles using Punica granatum peels extract: Effect on green peach Aphid. Environ Nanotechnol Monitor Manag 2016; 6: 95-8.

56. Kanude KR, Jain P. Biosynthesis of CdS nanoparticles using Murraya Koenigii leaf extract and their biological studies. Int J Sci Res 2017; 3: 5-10.

57. Keerthiharan D, Kolandasamy N, Nazeer AA, et al. Phytochemical Reduction of Heavy Metal Ion Cd 2+ to Stable CdO Using Ethanolic Extract of Limonia Acidissima Leaves and Antimicrobial Investigation Thereof. Limonia Acidissima. Deepa, SSRN. 2019, 3370136

58. Somasundaram G, Rajan J. Effectual role of Abelmoschus esculentus (Okra) extract on morphology, microbial and photocatalytic activities of CdO tetrahedral clogs. J Inorg Organometal P Mater 2018; 28: 152-67.

59. Karthik K, Dhanuskodi S, Gobinath C, et al. Andrographis paniculata extract mediated green synthesis of $\mathrm{CdO}$ nanoparticles and its electrochemical and antibacterial studies. J Mater Sci 2017; 28: 7991-8001.

60. Thema FT, Beukes P, Gurib-Fakim A, et al. Green synthesis of Monteponite CdO nanoparticles by Agathosma betulina natural extract. J Alloy Compd 2015; 646: 1043-8

61. Thovhogi N, Park E, Manikandan E, et al. Physical properties of CdO nanoparticles synthesized by green chemistry via Hibiscus Sabdariffa flower extract. J Alloy Compd 2016; 656: 314-20.

62. Somasundaram G, Rajan J, Sangaiya P, et al. Phytochemicals and morphological influence of aloe barbadensis miller extract capped biosynthesis of CdO nanosticks. J Inorg Organometal P Mater 2019; 29: 1862-73.

63. Permana YN, Yulizar Y. Potency of Parkia speciosa Hassk seed extract for green synthesis of $\mathrm{CdO}$ nanoparticles and its characterization. IOP Conference Series: Materials science and engineering 2017; 188: 012018.

64. Shivaji K, Mani S, Ponmurugan P, et al. Green-synthesis-derived CdS quantum dots using tea leaf extract: antimicrobial, bioimaging, and therapeutic applications in lung cancer cells. ACS Appl Nano Mater 2018; 1: 1683-93.

65. Baghayeri M, Mahdavi B, Hosseinpor-Mohsen Abadi $Z$, et al. Green synthesis of silver nanoparticles using water extract of Salvia leriifolia: Antibacterial studies and applications as catalysts in the electrochemical detection of nitrite. Appl Organometal Chem 2018; 32: e4057.

66. Seydi N, Mahdavi B, Paydarfard S, et al. Preparation, characterization, and assessment of cytotoxicity, antioxidant, antibacterial, antifungal, and cutaneous wound healing properties of titanium nanoparticles using aqueous extract of Ziziphora clinopodioides Lam leaves. Appl Organometal Chem 2019; 33: e5009.

67. Savale A, Ghotekar S, Pansambal S, et al. Green synthesis of fluorescent $\mathrm{CdO}$ nanoparticles using Leucaena leucocephala L. extract and their biological activities. J Bacteriol Mycol 2017; 5: 00148 